\title{
Sex differences in brain plasticity: a new hypothesis for sex ratio bias in autism
}

\author{
Laurent Mottron ${ }^{1,2,3,4^{*}+}$, Pauline Duret ${ }^{1,2,3,4,5^{\dagger}}$, Sophia Mueller ${ }^{6,7,8}$, Robert D Moore ${ }^{4,9,10}$, Baudouin Forgeot d'Arc Ar, $2,3,4^{\text {, }}$ \\ Sebastien Jacquemont ${ }^{4,11,12}$ and Lan Xiong ${ }^{3,4 \dagger}$
}

\begin{abstract}
Several observations support the hypothesis that differences in synaptic and regional cerebral plasticity between the sexes account for the high ratio of males to females in autism. First, males are more susceptible than females to perturbations in genes involved in synaptic plasticity. Second, sex-related differences in non-autistic brain structure and function are observed in highly variable regions, namely, the heteromodal associative cortices, and overlap with structural particularities and enhanced activity of perceptual associative regions in autistic individuals. Finally, functional cortical reallocations following brain lesions in non-autistic adults (for example, traumatic brain injury, multiple sclerosis) are sex-dependent. Interactions between genetic sex and hormones may therefore result in higher synaptic and consecutively regional plasticity in perceptual brain areas in males than in females. The onset of autism may largely involve mutations altering synaptic plasticity that create a plastic reaction affecting the most variable and sexually dimorphic brain regions. The sex ratio bias in autism may arise because males have a lower threshold than females for the development of this plastic reaction following a genetic or environmental event.
\end{abstract}

Keywords: Autism spectrum, Sex ratio, Male bias, Synaptic plasticity, Regional plasticity, Perceptual associative cortex, Sexual dimorphism, Enhanced perceptual functioning

\section{Review}

\section{Introduction}

Boys have a 4 to 7 higher-fold risk of developing autism than girls [1], (for a review see [2]). The 'protective effect' observed in females with respect to the autism spectrum (AS) remains largely unexplained [3]. X-linked variants have been explored as obvious candidates; however, the frequency of monogenic X-linked intellectual disability (ID) in AS is too low (5\% to $8 \%$ of males with autism) to account for the imbalance in the AS sex ratio [4-6]. The most preeminent hypothesis for the AS sex ratio, and other sex-specific associations in autism, is the extreme male brain (EMB) theory [7]. In this paper, we propose as an alternative the enhanced plasticity hypothesis (see Table 1 for a summary of these two theories), which is consistent with the EMB theory in some

\footnotetext{
*Correspondence: laurent.mottron@gmail.com

${ }^{\dagger}$ Equal contributors

${ }^{1}$ Centre d'excellence en Troubles envahissants du dévelopement de I'Université de Montréal (CETEDUM), Montréal, Canada

${ }^{2}$ Hôpital Rivière-des-Prairies, Département de Psychiatrie, Montréal, Canada Full list of author information is available at the end of the article
}

aspects and inconsistent in others. We focus on sex differences in plasticity at the synaptic and regional level and hypothesize that these differences influence the threshold for the development of plastic reactions in specific brain areas involved in perception and language.

\section{Background: the role of altered synaptic and regional plasticity in autistic cognitive hyper functioning}

Autism involves cognitive hyper-functioning and cortical reallocations [8], which have not yet been mechanistically related to sex. Regional plasticity, or cortical reallocation (the two terms are equivalent and will be used interchangeably in the text) correspond to the experience-dependent dedication of a cerebral region to a cognitive function that does not typically map to this region in the general population, for example cross-modal plasticity that occurs in sensory-impaired individuals [9]. Outstanding skills, including special isolated skills (SIS, clinically-defined domainspecific talents that contrast with an individual's overall level of functioning) in everyday life and perceptual peaks (PP) of performance in laboratory settings are frequent 
Table 1 Accounts of the enhanced plasticity hypothesis and extreme male brain theory to explain sex-related features in the autism spectrum

\begin{tabular}{llll}
\hline & Sex-related autistic features & Enhanced plasticity hypothesis & Extreme male brain theory \\
\hline Sex ratio & For every female, four to ten males are & Males have a lower threshold than females Autism reflects 'extreme expression of the \\
identified with autism. & for developing an enhanced plastic & reaction to the same biological event. This require fewer biological changes than \\
& reaction targets perceptual or language- & females to exhibit autism; strong empathy \\
& related cerebral regions, resulting in autistic skills protect women against autistic social & strength and social neglect. & deficits.
\end{tabular}

IQ/sex ratio The excess of males increases with 10 relationship

$\begin{array}{ll}\text { Social \& } & \text { AS males show more social and } \\ \text { communication } & \text { communication impairments than AS } \\ \text { phenotype } & \text { females. }\end{array}$

RRBI phenotype AS males show more RRBI than females.

Non hormonerelated genetic findings

Hormonerelated genetic findings

Brain structure

\section{Brain} connectivity

Brain function
Autism-related differences overlap with sexually dimorphic structures.

Many genes involved in autism are related to synaptic plasticity, and some show sexually-dimorphic expression.Deleterious and DN CNV/ SNV are more frequent in autistic females than males.

AS females and low-IQ males, but not high-IQ AS have a high incidence of DN LGD mutations.

A dozen sex-steroid pathway genes are associated with AS.

Connectivity patterns in AS resemble particularities of the brain network of non-autistic males.

Autism-related differences overlap with sexually dimorphic patterns of activation.
Severe mutations leading to low IQ mask any sex-differences. In high functioning AS, mutations are less deleterious, preserving normal, sexually dimorphic plasticity.

Social symptoms result from the neglect of socially-guided behaviors caused by the domination of perceptual (AS individuals with SOD) or language (AS individuals without SOD)-guided behaviors, which are in turn favored by strong experiencedependent plasticity in males.

Enhanced perceptual-functioning accounts for perception-based RRBI.

Perceptual regions are more likely to be targeted by the enhanced plastic reaction in males than in females.

Synaptic plasticity is expressed through different mechanisms in males and females throughout life. The 'genetic protective effect' in females contributes to the small sex-ratio in low-IQ autism.

Causative mutations are more likely to affect or trigger a plastic reaction in males than in females, because of the lower threshold of plasticity in males.

Deleterious mutations disrupt plasticity resulting in a similar phenotype, mostly composed of 'negative' signs, in low IQ males and females.

Sex steroids modulate plasticity mechanisms resulting from non-steroid related plasticity genes and thus can also be associated with autism.

Autism-related differences overlap with the most variable regions of the nonautistic brain. Differences in structure may reflect previous differences in plasticity mechanisms.

Connectivity reflects the way networks were organized by plasticity mechanisms mainly during development. Loci of enhanced connectivity are determined by loci of enhanced variability in humans.

Enhanced experience-dependent plasticity in associative perceptual (or language) regions, accounts for enhanced activity in autism. Given that these regions are among the most variable and plastic areas and underlie some of the most recent functions in evolution, they are likely to show group differences in activity like male/female or AS/non-AS dimorphisms.
Females with syndromic autism are easier to identify than those with high IQ autism because the social competence of women compensates for autistic social features.

Social symptoms result from strong expression of the non-autistic male social behavioral phenotype, which is less driven toward the social domain than that of females.

Some high-level RRBI are rule-based behaviors accounted for by extreme systematizing, a male strength.

Genetic differences unrelated to hormonal effects are not accounted for by the EMB model.

Genetic alteration of the sex-steroid pathway modifies fetal androgens levels, causing hyper-masculinization of the autistic brain.

Altered brain structure in AS results from hyper-masculinization.

Connectivity pattern in autism results from hyper-masculinization of the brain networks.

Altered activations sometimes show the pattern females $>$ males $>$ AS or AS $>$ males $>$ females, reflecting hypermasculinization of brain functions. 
Table 1 Accounts of the enhanced plasticity hypothesis and extreme male brain theory to explain sex-related features in the autism spectrum (Continued)

\begin{tabular}{|c|c|c|c|}
\hline Cognition & $\begin{array}{l}\text { Autistic strengths and non-autistic male } \\
\text { strengths overlap. } \\
\text { Scores in psychological tests show the } \\
\text { following patterns: } \\
\text { Systemizing/Autism Quotients: AS > } \\
\text { males > females } \\
\text { Empathy Quotient: } \\
\text { Females > males > AS }\end{array}$ & $\begin{array}{l}\text { This overlap is limited to some visuospatial } \\
\text { tasks. Autistic strengths extend beyond } \\
\text { male strengths, and manifest as enhanced } \\
\text { perceptual functioning, even in domains } \\
\text { where no clear male advantage is } \\
\text { reported (for example, pitch). } \\
\text { SQ/EQ/AQ tests are not sensitive enough } \\
\text { to distinguish male/female differences } \\
\text { from autism/control differences. }\end{array}$ & $\begin{array}{l}\text { AS individuals strongly express male } \\
\text { cognitive strengths and weaknesses. }\end{array}$ \\
\hline $\begin{array}{l}\text { Behavioral } \\
\text { phenotype }\end{array}$ & $\begin{array}{l}\text { Autistic males present more social } \\
\text { negative symptoms and positive } \\
\text { repetitive symptoms. }\end{array}$ & $\begin{array}{l}\text { Differences in male and female autistic } \\
\text { phenotype result from sex differences in } \\
\text { the target of the plastic reaction. }\end{array}$ & $\begin{array}{l}\text { Phenotypic gender differences reflect the } \\
\text { masculinization of autistic behavior. }\end{array}$ \\
\hline
\end{tabular}

In some domains, the two hypotheses are not mutually exclusive and represent complementary views. References: the current review, [7] and [217]. AS: Autism Spectrum; CNV: Copy Number Variant; DN: De Novo; EMB: Extreme Male Brain; IQ: Intelligence Quotient; LGD: Likely Gene Disruptive; RRBI: Repetitive, Restrictive Behaviors and Interests; SNV Single Nucleotide Variant, SOD: Speech Onset Delay.

features of autism. Some domain-specific skills, like absolute pitch, synesthesia, and hyperlexia, are so much more frequent in autistic than in non-autistic individuals that their combination may even be considered specific to autism [10]. In one study, the prevalence of SIS in a large group of 254 autistic individuals was $62.5 \%$ and that of PP (in a smaller group) was $58 \%$ (vs. $13 \%$ in controls). Performances in different low-level perceptual tasks co-vary, indicating that they may depend on a single domain-general factor [11]. The presence of an SIS in a particular modality is not associated with a PP in the same modality [12], which suggests that SIS and PP in autistic individuals involve a high level of brain plasticity, combining an experiencedependent component to genetically defined enhancement of perceptual encoding.

In addition to superior perceptual performance in many tasks, the functional allocation of some brain regions, in particular the visual associative cortex, is more extended and variable in autistic than in non-autistic individuals $[13,14]$. Together with idiosyncratic, individual-specific connectivity among functional regions [15], this high variability suggests regional reallocations of neuronal resources in autistic individuals. Using a quantitative meta-analysis of published functional imaging studies, we computed Activation Likelihood Estimation maps and found that activity in temporal, occipital, and parietal regions during a broad range of visual tasks was higher in autistic than in nonautistic individuals. By contrast, AS individuals exhibited less activity in the frontal cortex than non-autistic individuals. The spatial distribution of pattern differences between groups varied across processing domains. Autism may therefore be characterized by strong functional resource allocation in regions associated with visual processing and expertise [16].

The auditory modality provides further evidence for the plastic nature of autistic enhanced performance. When exposed to speech-like sounds, AS individuals with a speech onset delay showed high activity in the primary auditory cortex, whereas higher-order regions associated with language processing were highly active in AS individuals with normal language development. These findings suggest that cortical functional reallocations occurring in the most plastic brain regions, the multimodal association cortices[17], favor either perception or language, which may account for the main subgroups in the AS [18].

Enhanced performance and the autonomy of perception form the basis for the Enhanced Perceptual Functioning model (EPF) of autistic cognition [19]. This model proposes that the superior performance of autistic individuals in multiple basic perceptual tasks results from strong encoding mechanisms in a subset of low-level dimensions, associated with enhanced perceptual expertise and an atypically prominent role for perceptual mechanisms in cognitive function. Alternatively, in AS individuals without speech delay, incoming information is primarily processed by the hyper-functioning of typical language-related processes, resulting in language strengths, but not perceptual ones.

How may high regional plasticity result from mutations in AS-associated genes and microstructural brain plasticity mechanisms involved in autism? The TriggerThreshold-Target (TTT) model of autism [20] attempts to link the EPF model to strong synaptic and regional plasticity. According to the TTT model, several genetic mutations and environmental insults involved in autism upregulate synaptic plasticity [21-23]. At the microstructural level, synaptic plasticity (SP) is the process of constructing and pruning synapses that occurs during development and the remodeling of these synapses during learning. SP stabilizes new experiences and is therefore involved in the ongoing experience-dependent adaptation of perception and memory systems. A plastic reaction to genetic or environmental events promotes SP especially in individuals with a low threshold, resulting in functional reallocations that in turn lead to maximal adaptation 
following network disturbance. The term threshold here refers to the level of disruption required for this plastic reaction to happen. Similar mutations may be associated with different thresholds that may lead to substantially different phenotypes [24], particularly in males and females [25]. Here, we describe compelling direct and indirect evidence from human genetics and transcriptomics, animal models, brain imaging, and studies of cerebral plasticity in development and adulthood, supporting the hypothesis that this plastic reaction is sex-dependent. We suggest that plasticity is involved in autistic sex-ratio bias because males have a lower threshold than females for the development of plastic reactions.

\section{Sex differences in synaptic plasticity: human genomic data and animal models of autism \\ Autism-associated genetic mutations involved in synaptic structure, function, and plasticity}

Large-scale whole-exome sequencing (WES) and genomewide copy-number variant (CNV) studies of autism have identified highly penetrant de novo gene-disrupting mutations in about $30 \%$ of simplex AS cases. Such mutations in approximately 400 genes contribute to autism [26-33]. Transcriptomic analyses have revealed that these genes are important for synaptic structures and functions, which may affect specific brain regions and neural circuits associated with learning, memory, and perception [34-39]. These include: (1) FMRP targets, that is, transcripts bound by the fragile $\mathrm{X}$ mental retardation protein (FMRP) which locally regulates the transport, stability, and/or translation rate of more than 850 brain mRNAs at the synapse, many of which are linked to synaptic function [32,33,40]; (2) genes involved in chromatin remodeling and those encoding chromatin modifiers [31,32]; (3) synaptic function and plasticity genes, in particular genes encoding postsynaptic density proteins $[31,32,41]$; (4) genes regulating transcription and splicing that are expressed preferentially in embryos [31,32,42,43]; and (5) embryonic development genes [44]. According to our model, these mutations represent the Trigger of a sexually dimorphic plastic reaction.

\section{Sexual dimorphism in the expression of genes related to AS}

The brain transcriptome of males and females differs throughout life, in particular during development. In a spatiotemporal transcriptomic study of the human brain, Kang et al. [43] identified 159 genes differentially expressed between males and females located on the $\mathrm{Y}$ (13 genes, 8.2\%), $\mathrm{X}$ (nine genes, 5.7\%), or autosomal (137 genes, 86.2\%) chromosomes. The expression of many of these genes (76.7\%) was higher in males than in females and notable topographical differences were observed. More genes showed sex-biased expression during prenatal development than during postnatal life, with the adult brain showing the fewest differences in expression. The largest differences were attributable to $\mathrm{Y}$ chromosome genes, especially $P C D H 11 Y$, RPS4Y1, USP9Y, DDX3Y, NLGN4Y, UTY, EIF1AY, and $Z F Y$. These genes displayed constant expression across brain regions during development and life, and their functional homologues on the $\mathrm{X}$ chromosome were not upregulated in a compensatory manner in female brains. These profiles indicate that the main differences in brain development between the sexes happen during the prenatal period and are largely determined by the differential expression of genes on the sex chromosomes, although many other genes on autosomes may also contribute. Furthermore, in some genes the exons show sex-specific patterns of expression in the brain. Although the exact role of most of these sex-differentially expressed genes in brain development is not yet known, some are relevant to the pathogenic pathways of autism. For example, the NLGN4X gene is expressed in males and females at a similar level, but some of its exons are more strongly expressed in males in a developmentally regulated manner. Exon 7 and, to a lesser extent, exons 1,5 , and 6 of $N L G N 4 X$ are gradually more expressed in males than in females, from the prenatal period to adulthood. A frameshift mutation (1186insT) was identified in exon 6 of NLGN4 in one Swedish family with two affected brothers, one with typical autism and the other with Asperger syndrome [45]. Another 2-base-pair frameshift deletion (1253del(AG)) was also found in exon 5 of NLGN4X in 13 affected males with ASD and ID [46]. The R704C mutation of NLGN4, which is found in some autistic individuals may act by enhancing synaptic transmission [47]. The NLGN4 gene belongs to the neuroligin family of cell adhesion molecules, which are located postsynaptically and bind to presynaptic neurexins [48] and netrins [49] to form trans-synaptic complexes. In mice, NLGN4 is involved in the regulation of excitatory and inhibitory circuits and helps to balance the response to stimulation [50]; thus, this gene is important for reactive plasticity.

In another transcriptomic analysis of male-female differences in prefrontal cortical development, Weickert et al. [51] identified $14 \mathrm{Y}$ and $11 \mathrm{X}$ chromosome genes showing sexually-dimorphic expression, including many genes implicated in autism, such as NLGN4Y and PCHD11Y, which were highly expressed in infant males and may influence the early male-specific development of cortical brain cells. $P C D H 11 X / Y$ is a human-specific gene pair located in the Xq21.3/Yp11.2 homologue region [52,53] mainly expressed in the brain [53,54]. Like other cadherin genes, $P C D H 11 X / Y$ is localized at the synaptic junction and probably involved in the regionalization and functional differentiation of brain gray matter and in the establishment of neuronal connections or signal transduction at the synaptic membrane. $P C D H 11 X$ transcripts are more abundant in females than in males [55]. However, a longitudinal study of the human prefrontal cortex showed that 
PCDH11X transcript levels were highest in newborn males, decreased throughout childhood, and were equally low in adults of both sexes [51]. Duplication and deletion of this region are associated with both developmental dyslexia [56] and non-syndromic language delay [57].

Altogether, these findings show that developmentally and spatially regulated differences in gene- and exonlevel expression exist between male and female brains in specific regions and may have irreversible effects on cerebral architecture and plasticity. Therefore, sex differences in the temporal and spatial transcriptomic profile of the human brain during early development may modulate an individual's vulnerability and reactivity to genetic and environmental perturbations. Spatial differences may determine the target regions of a plastic reaction, and temporal differences may influence the developmental course of its phenotypic manifestation.

\section{High mutational burden in autistic females}

A study of more than 9,000 dizygotic twins from population-based cohorts showed that siblings of autistic females exhibit significantly more autistic traits than siblings of autistic males [58-60], suggesting that female patients carry a higher 'genetic load' than male patients. Studies of chromosomal structural variation showed that de novo $\mathrm{CNV}$ are more common in autistic females than in autistic males and that these CNV disrupt more genes in females than in males [61-63]. Data on the following microdeletions in SHANK1 suggest that the penetrance of AS in these CNV carriers is sex-biased: four male carriers from the same family and another unrelated male carrier of a different microdeletion presented highfunctioning autism, whereas two female relatives carrying the same microdeletion showed anxiety but did not meet the diagnostic criteria for AS [64]. In a large CNV analysis of autistic individuals and their families, Pinto et al. [65] found that autistic females were more likely to have highly penetrant CNV and were twice as likely to have exonic deletions involving FMRP targets than autistic males.

In a cohort of 15,585 probands with neurodevelopmental disorders, Jacquemont et al. [66] found that deleterious autosomal CNV were more common in females than in males. Furthermore, in an independent AS cohort of 762 families, females had three times more deleterious autosomal $\mathrm{CNV}$ and many more unique deleterious single-nucleotide variants (SNV) than males. The effect of autosomal SNV was also substantially more severe in autistic females than in autistic males. Consistent with the notion of a protective effect in females, inherited deleterious CNV and SNV in AS individuals and those with other neurodevelopmental conditions are preferentially of maternal origin. Two recent WES analyses of AS confirm this observation [31,32]. These studies show that both autistic females and males with a low IQ have a high incidence of de novo (DN) likely gene disruptive (LGD) mutations. However, there were few DN LGD mutations in high-functioning males with AS. These observations suggest that gene disruptive variants, which have been the focus of recent exome studies, are strongly associated with IQ and do not make a significant contribution to AS without ID. Less deleterious variants such as inherited missense variants are more difficult to validate (because they require much larger case-control samples) but may contribute to AS in individuals of average intelligence, which is the category of individuals showing the strongest sex bias in AS [67]. For example, Berkel et al. identified seven missense variants at highly conserved positions in SHANK2 only in AS individuals, most of which were transmitted by unaffected mothers [68].

Mutations present in AS males with a low IQ overlap with those found in females but not with those found in AS individuals with a high IQ, demonstrating that sex ratio bias in AS mostly involves high-functioning individuals [67]. Therefore, the AS sex ratio cannot be explained by a genetic mechanism resulting from severe loss of function mutations found in AS individuals with a low IQ, but rather by factors present in AS individuals without ID, in whom severe loss of function mutations have not been found and SIS and PP are consistently reported.

\section{Sex differences in synaptic plasticity observed in animal models of AS-associated genes and insults}

Although animal models far from capture the complex and heterogeneous human autistic features and are mostly based on syndromic autism with ID, some of them reveal sex differences in synaptic plasticity and thus provide important information about the underlying pathogenic pathways of AS. Furthermore, they constitute promising models to fill the gap between genetically-triggered microstructural alterations and regional plasticity. Indeed, a murine model of autism, known for its structural and connectomic particularities (cortical thickening and loss of the corpus callosum connections), demonstrated shifts in the location of two functional sensory regions [69].

\section{Fmr1 knockout mice}

Fragile X syndrome (FXS) is the most common form of inherited ID and a leading cause of 'syndromic' autism with ID [70]. FXS occurs in both sexes, but women are usually less affected than men because of compensation by the normal FMR1 gene on the second X chromosome. This disorder is caused by the loss of the X-linked FMR1 gene product, fragile $\mathrm{X}$ mental retardation protein (FMRP), a mRNA-binding protein involved in translational regulation that plays a crucial role in brain development, synaptogenesis, and synaptic pruning [21,71]. 
FMRP represses the synthesis of proteins required for protein synthesis-dependent synaptic plasticity and acts as a switch to enable translation in response to synaptic signals [72]. Fmr1 knockout (KO) mice (mostly males) exhibit abnormal synaptic plasticity. long-term depression (LTD) of synaptic transmission is enhanced in the hippocampus [73] and the cerebellum [74], whereas long-term potentiation, (LTP) the most studied form of plastic strengthening of synapses, is impaired in the cortex [75-79] and the amygdala [77]. The abundance of calbindin in the dorsal thalamus is substantially lower in Fmr1 KO male mice than in female Fmr1 KO or control mice [80]. Neurons in the dorsal thalamus are glutamatergic, and low levels of calbindin may affect the functional properties of the circuits in which they are involved, for example by inducing long-term changes in the efficacy of excitatory synapses. Thus, Fmr1KO mice show male-specific abnormalities of synaptic plastic reactions probably because of the loss of Fmrp and the lack of gene dosage compensation from a second $\mathrm{X}$ chromosome.

FXS is therefore an example of differential plasticity between the sexes triggered by a genetic insult, where males are more susceptible to develop the syndrome than females. The compensatory role of the intact $\mathrm{X}$ chromosome in females does not explain why autism sometimes occurs in combination with FXS. Thus, other sex-related differences in plasticity may act in combination with the loss of FMRP to determine whether FXS occurs alone or with autism.

\section{SHANK genes animal models}

SHANK genes code for large synaptic scaffold proteins and bind to many proteins at the post-synaptic density (PSD) of excitatory synapses. Numerous deleterious mutations have been discovered in SHANK genes in AS and other neurodevelopmental disorders. Recent meta-analyses and review articles have shown that there is a gradient of severity in cognitive impairment, as well as sex ratio, in AS individuals carrying mutations in SHANK genes. Mutations in SHANK1 are only present in males with a normal IQ and autism. Mutations in SHANK2 are found in AS patients with mild ID, with a high male to female ratio. Finally, mutations in SHANK3 are found in AS individuals with moderate to profound ID, with an almost equal male to female ratio [81]. Shank1 mice show altered post-synaptic density (PSD) protein composition, small dendritic spines, and weak basal synaptic transmission [82]. Spatial learning and memory are better in Shank1-/- male mice than in Shank1-/- female mice [83], indicating a hyperplastic reaction in memory formation in males. Deletion of Shank2 in mice results in an early, region-specific upregulation of ionotropic glutamate receptors at the synapse and high levels of Shank3. Moreover, Shank2-/- mutants exhibit fewer than normal dendritic spines, impaired basal synaptic transmission, and disrupted postsynaptic currents [84]. Mice with Shank3 gene deletions exhibit selfharming behavior, repetitive grooming, and deficits in social interaction. Cellular, electrophysiological, and biochemical analyses have uncovered defects at striatal synapses and cortico-striatal circuits in Shank3 mutant mice [85]. Therefore, knockout-mice models of Shank genes indicate that each gene plays an important and sex-specific role in synaptic plasticity. However, these sex differences may not be observable in $\mathrm{KO}$ models because of the major deleterious effects of these mutations.

\section{The VPA animal model}

The valproic acid (VPA) model [86] is the most extensively studied animal model of autism (for a review see $[87,88])$. This model is insult-based and does not involve major genetic modifications; therefore, it allows the investigation of synaptic plasticity pathways in a wild-type background. A single prenatal injection of VPA on embryonic day 11.5 significantly stimulates the local recurrent connectivity of neocortical pyramidal neurons but limits the strength of the connections [89]. Hyperconnectivity and hyperplasticity in the medial prefrontal cortex, the somatosensory cortex, and the lateral amygdala have also been observed in this model $[90,91]$. Synaptic plasticity experiments between pairs of pyramidal neurons have revealed the existence of a strong postsynaptic form of LTP in mice exposed to VPA in utero [89]. Rinaldi et al. [92] subsequently reported the selective overexpression of two subunits of the NMDA receptor and the commonly linked kinase calcium/calmodulin-dependent protein kinase II, indicating that VPA strongly stimulates NMDA receptormediated transmission and promotes plasticity in the neocortex. Mowery et al. [93] also found higher cell counts in male than in female VPA rats, indicating a stronger but more aberrant local plastic reaction to VPA in males.

Sex-specific behavioral and immunological alterations have been observed in the VPA model [94]. VPA promotes neural progenitor-cell proliferation and induces macrocephaly in rat brains via a mechanism involving the GSK-3 $\beta / \beta$-catenin pathway [95]. In particular, malespecific alterations in excitatory post-synaptic development and social interactions have been observed [96]. Moreover, VPA-exposed male offspring show hyperactivity and strongly impaired social interactions whereas the phenotype of female offspring is less pronounced. The expression of the GABAergic neuronal marker GAD is low and that of the glutamatergic neuronal marker vGluT1 is high in both male and female rats, but post-synaptic markers such as PSD-95 and $\alpha-$ CAMKII are strongly expressed only in male offspring. Electron microscopy detected a higher than normal 
number of post-synaptic compartments in males but not in females at 4 weeks of age, suggesting that the altered glutamatergic neuronal differentiation leads to perturbations of post-synaptic maturation only in male offspring prenatally exposed to VPA. Male VPAexposed rats are more sensitive than females to electric shock, consistent with the large size of the postsynaptic compartment in males [96].

Male rats exposed prenatally to VPA frequently develop an abnormally large number of glutamatergic synapses. Kim et al. [97] recently showed that methylCpG-binding protein 2 (MeCP2) influences sex differences in postsynaptic development in the VPA animal model of autism. MeCP2 loss-of-function causes Rett syndrome in girls [98]. VPA exposure leads to malespecific abnormalities in the timing of excitatory glutamatergic synaptic protein expression and results in male-specific attenuation of MeCP2 expression both in the prefrontal cortex of offspring and in neural progenitor cells (NPCs). Furthermore, small interfering RNA (siRNA) against Mecp2 inhibits Mecp2 expression in male-derived NPCs, resulting in the induction of postsynaptic proteins such as PSD95 but has no effect on female-derived NPCs. Thus, low Mecp 2 expression in males is involved in the abnormal development of glutamatergic synapses, which may explain why males show more abnormalities than females in VPA animal models of AS. Protective effects of estrogen and progesterone and sex-related differences in the development and/or functioning of neurotransmitter systems may also play a crucial role in the protection of female rats from VPAinduced aberrations [94].

\section{Sex differences and autism-specific aspects of brain architecture and function \\ Typical structural and connectome sex differences Developmental changes in gray matter structure}

The cortex attains its maximal complexity just after birth, but soon undergoes global thinning and a decrease of gyrification until early adulthood [99]. This global pruning is accompanied by the building and reinforcement of neural circuits through experience-dependent neurogenesis and synaptogenesis [100]. No sex differences have been reported in the developmental trajectories of overall cortical volume, thickness, and surface area [101]. By contrast, sex differences have been observed in specific regions. A recent longitudinal study examined deep changes of gyrification occurring in infants from birth to 2 years of age [102]. Sex differences were observed at birth around the calcarine fissure and at 2 years of age in the left paracentral cortex. Large increases of gyrification occurred in multimodal association cortices (prefrontal, temporal, inferior parietal, and precuneus) which, in contrast to unimodal regions, were not mature at birth. These regions are more likely to be reshaped by environmental factors because they are less genetically constrained than primary regions [103] and also because immature systems tend to incorporate information from the environment and from personal experience into their structure and function $[100,104]$. Other studies have shown that cortical modifications occurring from childhood to adulthood differ according to sex $[105,106]$. Males show a larger decrease of gyrification than females specifically in the right pre-frontal cortex. Thickness changes are even more dependent on sex; in females, temporal and frontal lobes show a high rate of thinning whereas in males, thinning is faster in the occipital lobe [105]. Raznahan et al. [105,106] found that most frontal regions matured earlier in females than males, whereas the opposite was true for a large posterior temporal and parieto-occipital area. These late-maturing regions showed accelerated thinning during adolescence corresponding to networks underlying cognitive functions for which the 'late' sex tended to perform less well. These two results reveal the sex-related differences of developmental trajectories of the frontal brain as opposed to the perceptual associative areas. In addition, the volume of the mature human brain is smaller in females than in males, but females display greater gyrification and thickness [107-109]. These two latter features may merely reflect the optimization of space in a smaller intra-cranial volume in females; however, they may also be related to functional sex-specific cognitive strengths because gyrification reflects microstructural organization. Taken together, these findings demonstrate the existence of developmental time windows during which particular brain regions exhibit high levels of plasticity in a sex-dependent fashion.

\section{Connectome and white matter findings}

Boys have a larger callosal volume than girls at birth [110] and faster or more pronounced increases in white matter volume during development [111]. Sex differences in white matter fibers were recently studied in a large sample of individuals between 8 and 22 years old [112]. This study shows that cortical wiring differs between sexes; intrahemispheric connections were dominant in males whereas inter-hemispheric connections dominated in females. Male networks showed a highly modular organization, with strong local cross-talk, whereas female networks were more strongly connected between lobes, although the inverse pattern was found in the cerebellum. The modular organization of the male connectome was detected from early adolescence, starting in the temporo-parietal regions and later spreading from the occipital to posterior frontal regions. Recent functional connectivity results confirm these findings and show that females have greater overall connectivity density than males at rest, meaning that each region is connected to a higher number of nodes in females than in males [113]. 
Moreover, connectivity inside functional networks (that is, brain regions that may be distant from each other but work together to perform a particular function) is higher in females than in males (males show instead more extensive between-network connectivity) [114]. This indicates that female functional networks tend to be more segregated, which is also the case for structural connectivity [115]. Nevertheless, other results indicate that local connectivity is more efficient in females than in males $[116,117]$. Regional sex differences in connectivity efficiency largely involve the association cortices [117]. One study investigating task-related connectivity found a differential relationship in girls and boys between connections in the auditory system and IQ. In boys, intelligence was related to the connection between Broca's area and auditory processing regions, whereas in girls it involved the connection between the right posterior temporal gyrus and other auditory areas [115]. Conversely, a meta-analysis based on three different measures of functional connectivity and using data from over 1,000 non-autistic individuals demonstrated the existence of region-specific sexually dimorphic connectivity; for instance, males have higher connectivity in occipital and temporal regions than females [118] (see Figure 1F).

\section{Autism-specific aspects of brain structure, connectivity and development overlapping with sex differences Connectivity findings}

Alterations in network connectivity are consistently found in autistic individuals (as recently reviewed in [119]). Compromised white matter integrity (see [120-122]) coupled with long-range hypo-connectivity counterbalanced by local hyper-connectivity [123-125] are commonly found in autistic individuals. However, studies examining connectivity in autism report some inconsistent results and their conclusions may differ according to the method used to assess connectivity [126]. Consequently, we only report here recent results that parallel sex differences reported in 2.1 or related to AS hyper-functioning. Based on previous results showing that thickness correlations between regions are related to anatomical connections, Shi et al. [127] found that in AS children, thickness correlations between regions of the same functional network were lower whereas those outside networks were higher than in typically developing children. This finding was replicated by Zhou et al. [128] who further reported that functional connectivity between some individual regions is low in AS, but the overall efficiency of networks in AS and nonautistic children according to functional activity is similar. Thus, alternative connections in the autistic brain enable atypical, although effective cognition. Local connectivity alterations are certainly related to autism. For instance, only individuals with autism, with or without tuberous sclerosis, show a low ratio of long over short-range coherence of EEG connectivity, which is absent in individuals with tuberous sclerosis alone [129].

Measurements of resting-state functional and structural connectivity indicated that the brain networks of AS individuals may be less functionally differentiated than those of non-autistic individuals $[126,130]$. However, studies of task-related functional connectivity do not support this statement. For instance, both short and long-range occipital hyper-connectivity were observed in AS individuals during visual search, a task related to a hyper-functioning cognitive domain in autism [131]. In studies examining regional measures of functional connectivity, hyper-connectivity has been often reported in autistic individuals in regions related to the visual system. In AS individuals, the visual cortex has many internal connections (Figure 1D, [132-134]) and is highly connected to the frontal lobe $[135,136]$. Furthermore, AS individuals show high connectivity between associative perceptual regions such as the parietal and temporal lobes [137] and inside the medial temporal cortex [138].

Low inter-hemispheric functional connectivity (probably resulting from low callosal volume [139]) has been found in AS individuals [140]. Rudie et al. [141] examined functional connectivity and reported that both the overall and local 'efficiency' of autistic brain networks was low, confirming that the segregation of brain systems is less defined in AS than in non-autistic individuals. However, their results regarding anatomical connectivity (measured by DTI) revealed a different pattern, which demonstrates the importance of comparing similar measures when analyzing connectivity. In non-autistic individuals, the brain tended to switch from a modular to a more globally efficient structural organization during adolescence, whereas AS networks tended to keep their modular organization. An EEG connectivity study also reported that the organization of the brain of AS individuals was highly modular [124].

\section{Developmental findings}

General cerebral overgrowth of gray and white matter has been consistently observed in autistic children during the first years of life (for a review see [142]), as recently illustrated by measurements of high surface area in AS [143]. This early growth stage is very relevant; the peak of synaptogenesis occurs at this stage [100] where the first observable structural sex differences emerge. In addition, it is also the stage at which the first detectable clinical and behavioral signs of autism appear [144]. Perceptual signs such as long visual fixations are among the first to 

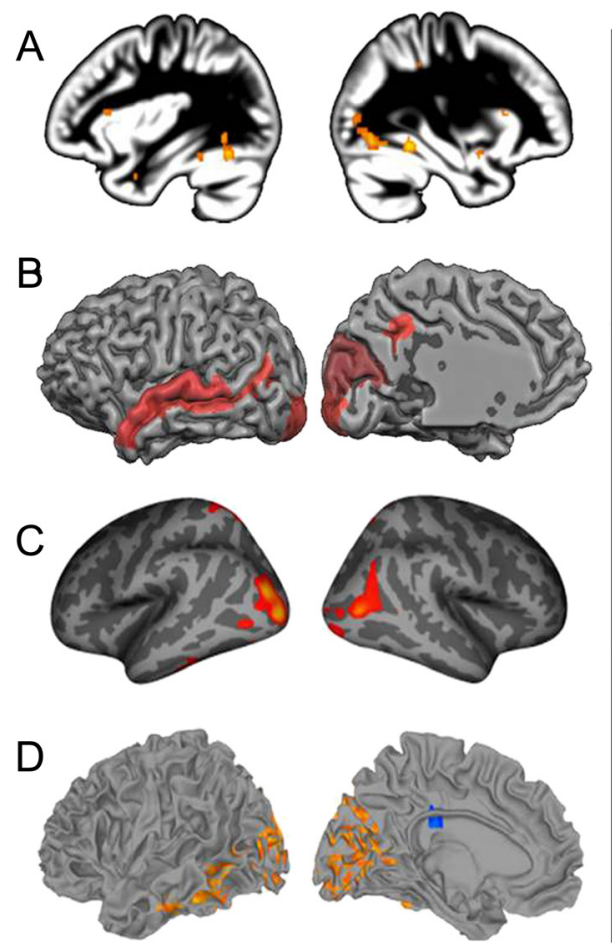

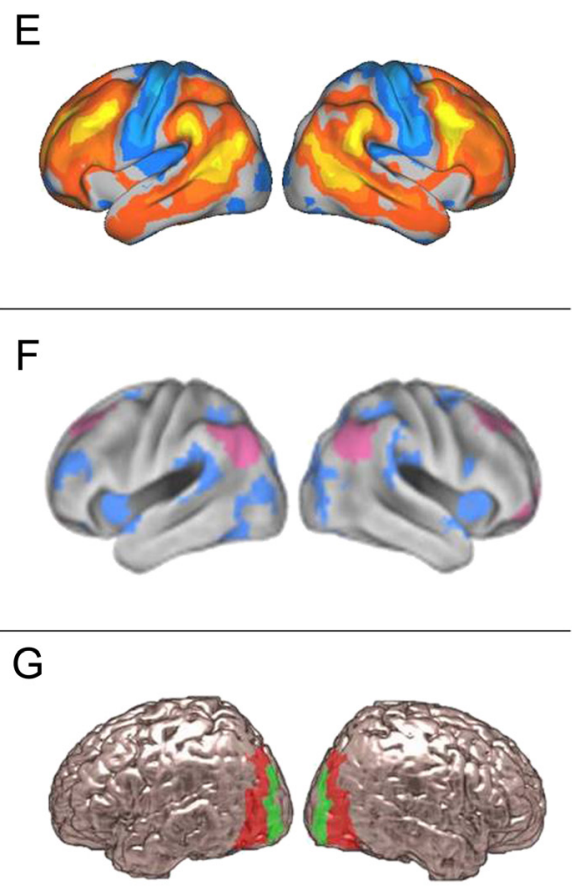

Figure 1 Convergence between functional (A), structural (B,C), and connectivity (D) regions of interest in autism and regions of maximal variability (E) and sexual dimorphism (F) in typical individuals in a visual associative area (G). (A) Regions showing more activity in autistic individuals than in non-autistic controls when processing visual information. Qualitative meta-analysis, whole brain FDR corrected [16]. (B) Regions showing greater cortical gyrification in autistic individuals than in non-autistic individuals. The warmer the color, the greater the significance of the group differences [152]. (C) Regions showing higher thickness in autistic versus non-autistic individuals. More than 1,000 brains analyzed, FDR corrected [151]. (D) Regions of enhanced resting-state local connectivity density in autistic individuals. Warm colors show the regions with greater connectivity in the autistic individuals than in non-autistic individuals, and cool colors regions of lower connectivity [134]. (E) High inter-individual variability in resting-state functional connectivity in non-autistic individuals. Values above or below the global mean are displayed in warm and cool colors, respectively [17]. (F) Regions of higher resting-state functional connectivity in males (blue) and females (pink). Seed-based analysis on more than 1,000 brains corrected with Gaussian random-field theory [118]. (G) Bilateral visual associative cortex: Brodmann Areas 18 (green) and 19 (red).

manifest at around nine months of age [145], and brain overgrowth peaks at the same time [146]. The negative social and speech symptoms of autism are detected on average around one year later. Courchesne et al. [147] further showed that this overgrowth mainly involves frontal and temporal cortices, whereas parietal and occipital cortices were largely unaffected. However, during adolescence this overgrowth was followed by an accelerated decrease of volume. Other studies also have reported perturbations of gray matter development in AS individuals during childhood and adolescence involving either precocious maturation [148] or accelerated decrease in the volume of particular regions, with the most striking differences localized to the occipital cortex [149]. Taken together, the developmental course of structural alterations reported in autism show that the manifestations of autism mainly involving overt socio-communicative 'negative' signs are visible after a period of structural overdevelopment.

\section{Structural findings in the mature autistic brain}

Only one study to date has compared anatomical differences between both males and females and autistic and non-autistic individuals [150]. This study focused on local volumetric measures and found several regions showing volume differences between the sexes. Autistic and non-autistic individuals showed few volumetric differences and there was no overlap between atypical structures in autistic males and sexually dimorphic structures in controls, although gray matter showed small overlap between autistic females and sexually dimorphic structures in controls. This overlap was more pronounced in white matter. Cerebral volume is perhaps not the best measure to assess similarities between sexually dimorphic and autism-specific structural alterations.

Examination of the structure of the mature cortex indicates that the occipito-temporal and parietal regions are thicker (Figure 1B) [151], and gyrification in the precuneus and occipito-temporal areas is more pronounced in autistic than in non-autistic individuals (Figure 1C) [152]. 
Voxel-based morphometry meta-analyses have also revealed volume abnormalities in regions including the occipital, parietal, and temporal lobes [153] together with low frontal and high occipital gray and white matter volume in autistic individuals [154]. Additionally, the intraparietal sulcus and the parietal operculum have been found to be deeper in individuals with Asperger syndrome and autism, respectively, than in controls [155]. Differences in geometrical measurements have also been found in the central, frontal, medial, and intra-parietal sulci and in the developmental trajectory of these regions between autistic individuals and controls [156].

\section{Topographical convergence between sexually dimorphic, highly variable brain regions and those showing differences between autistic and non-autistic individuals}

In the two previous sections, we listed the striking similarities between male-female and AS-non AS differences in brain imaging areas that are related to plasticity mechanisms, and proposed that structure and connectivity patterns in the mature brain reflect previous experiencedependent plasticity. Although indirect, this evidence suggests that the idea of a central role of cerebral plasticity in AS male bias, based on genetic and animal findings, can be extended to human cognition. Indeed, qualitative examination of structural and functional differences between autistic and non-autistic individuals indicates a striking overlap between regions of major anatomical, connectivity-related and even functional (Figure 1A [16]) alterations in autistic individuals, and regions of cross modal plasticity in non-autistic, sensory-impaired individuals [157]. These overlapping regions, all of which involve perceptual associative areas, also overlap with regions showing (1) high variability of functional activation in autistic individuals [13]; (2) high inter-individual variability in resting-state functional connectivity in non-autistic individuals of either sex (Figure 1E [17]); and (3) higher connectivity in males than in females (see Figures 1 and 2). This overlap is indirect, although promising evidence of the following notion that is central to the TTT model [20]; enhanced cognitive performances in autistic individuals result from an enhancement of experience-dependent plasticity mechanisms, targeting perceptual associative regions. This model supports the hypothesis that early overgrowth, supposedly hyperplasticity originating prenatally, prevents the experience-dependent shaping of the brain in frontal regions, resulting in (and subsequently further reinforcing) autistic social impairments [142]. The implicated regions overlap with the sexually dimorphic regions in non-autistic individuals, in particular, the developmental opposition between 'social' (frontal and superior temporal) and perceptual (parieto-occipital and inferior temporal) regions. A sex-dependent plasticity imbalance between these regions may thus be central to the onset of autism.

Sexual divergence of developmental trajectories also suggests that the plastic reaction happens in different regions in boys and girls, resulting in a different autistic phenotype in men and women. This explains why males and females may be diagnosed according to different symptoms and/or using different weights attributed to the three diagnostic areas $[158,159]$. A meta-analysis of studies investigating sex differences in ASD symptoms concluded that males and females had similar communication and social symptoms, but girls showed fewer repetitive, restricted behaviors [160] and interests (RRBI) than boys. This finding is most frequently reported in studies including adolescents [161] and adults of typical intelligence [162], suggesting that compensatory social communication strategies develop over time, especially in girls [163].

\section{Hormonal effects involved in sexual dimorphism of brain regional plasticity}

We will now review sex differences in fetal hormonal effects, memory formation, stress response plasticity, and reaction to brain injury in adults. These sex differences
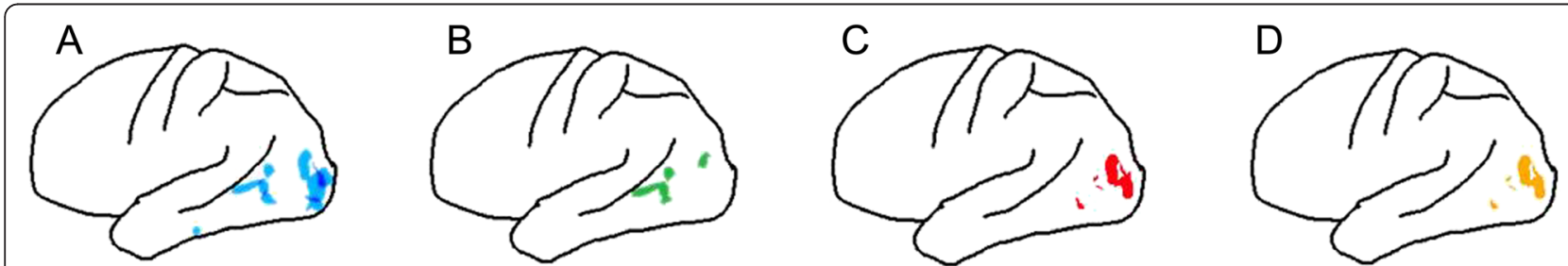

Figure 2 Topographical overlap between functional, structural, and connectomic particularities in the autistic left-hemisphere (A) and regions of high variability (B) and sexual dimorphism (C) in the general population in a visual associative area (D). Patterns of this schematic representation were obtained by manual alignment, distortion and superimposition of the results from the different relevant studies presented in Figure 1. (A) Overlap between two (light blue) or more (dark blue) autistic particularities out of four studies reporting higher thickness [151], gyrification [152], functional activity [16], and connectivity [134] in autism (left panel in Figure 1). (B) Overlap between the autism-specific region defined in $A$ and regions of high inter-individual variability in connectivity ([17] and Figure 1E). (C) Overlap between the autism-specific region defined in A and regions of higher connectivity in males ([118] and Figure 1F). (D) Overlap between the region defined in C and the visual associative regions (Brodmann Areas 18 and 19, Figure 1G). 
result from both hormonal and non hormonal sexspecific mechanisms of brain plasticity, which lead to a sex difference in the adaptive response of the brain to several types of injury, regardless of age.

\section{Fetal hormonal effects and their relevance to the onset of autism}

The brain is influenced by maternal, placental, and fetal hormones during early development [164]. Developing testes are more active than ovaries, resulting in higher levels of circulating testosterone (T) and estradiol in male than in female fetuses. Consequently, many studies have focused on the effects of these masculinizing hormones on brain development, despite the involvement of other hormones such as progesterone. Prenatal hormones thus affect neuronal cell proliferation, localization, apoptosis, and synaptic plasticity in a sexually dimorphic manner. Currently, no direct evidence in humans exists to show that these hormones contribute to sex differences in cerebral regions; however, studies in rodents and other animal models have shown that several regions showing sex differences, including the sexually dimorphic nucleus of the preoptic area [165] and hypothalamic structures, are organized prenatally by sex hormones. Some of these prenatal effects are irreversible and some of them only appear at adolescence following their reactivation by increases in steroid hormone concentrations (for a review see $[164,165])$.

According to the extreme male brain (EMB) theory, the effect of fetal testosterone (fT) may account for male bias in autism ([166,167]; see Table 1$)$. This theory posits that female brains are optimized for 'empathizing' whereas male brains are optimized for 'systemizing'. Empathizing refers to the capacity of identifying, understanding, and reacting correctly to another individual's thoughts and emotion, and systemizing is the ability to understand and predict the functioning of a law-driven system. Here, the autistic brain is an example of a hyper-systemizing brain which has been masculinized by high levels of fT during gestation [7]. Preliminary evidence of high levels of fT (and other androgenic hormones) in males with autism was only found recently [168]. These overall differences were detected at the group level. Androgen levels in individuals with autism, Asperger, or pervasive developmental disorders largely overlap with those of control individuals, suggesting that high $\mathrm{fT}$ is a susceptibility factor and not necessarily a direct cause of autism. Autistic females are also more likely to develop steroid-related conditions, such as polycystic ovary syndrome, than non-autistic females, further suggesting that exposure to abnormal levels of androgens is associated with autism [169]. However, a recent comprehensive review found only a weak link between steroid-related disorders and autistic traits and showed that the prevalence of autism is not high in clinical populations exposed to high androgen levels [164].

The complex role of $\mathrm{fT}$ in autism has been further documented in a rat model in which a hyper-androgenic environment was created by high $\mathrm{T}$ levels during pregnancy [170]. This impaired the vocalization behavior of rat pups of both sexes. In adolescence, the female offspring spent less time engaging in social interactions and exhibited impaired heterosexual interactions as adults. Although the affected behaviors can be classified as social, this model does not mimic the complexity of autistic features in humans. Furthermore, the social impairments in this rat model disappeared in adulthood. Nevertheless, these results indicate the sexually dimorphic consequences of high $\mathrm{T}$ levels. Thus, similar hormone levels probably have differential effects in males and females, mainly because of the compensatory reduction of $\mathrm{T}$ production in the male fetus in response to high maternal exposure, which cannot occur in the female fetus. Alternatively, in males, high $\mathrm{T}$ levels may not be sufficient to produce autistic-like behaviors and other mechanisms may be necessary. In summary, interactions between hormones and genes should be considered in the physiopathology of autism. For instance, androgens and estrogens differentially regulate the RORA gene, a candidate susceptibility gene for autism, the expression of which is low in the frontal cortex of autistic individuals [171]. The product of this gene, which promotes the conversion of $\mathrm{T}$ into estrogen, also acts through coactivators, demonstrating the complexity of the gene/ hormone interactions [172].

\section{Sex differences in memory formation and stress response plasticity driven by hormones: the hippocampus}

Sensory experience drives the formation and elimination of synapses resulting in experience-dependent plasticity [173]. Plasticity differences between the sexes have been extensively studied in the hippocampus. For instance, $\mathrm{Ca} 2+/ \mathrm{cal}-$ modulin kinase alpha (CaMKKa) and beta $(\mathrm{CaMKKb})$ are required for memory formation in male, but not female mice. $\mathrm{CaMKKb}$ activates the ubiquitous transcription factor regulator cAMP response element-binding protein (CREB) to regulate the formation of spatial memory specifically in males, thus resulting in sex differences in the activation of gene transcription. Conversely, estrogen promotes the formation of dendritic spines on CA1 pyramidal cell dendrites in adult female rats only [174]. Furthermore, estrogen has various actions on adult hippocampal neurogenesis, synaptic plasticity in the hippocampus, and cognition in female rats [175]. Estradiol synthesis is associated with synapse density in in vitro cultures of rat hippocampus from either sex, whereas synaptic loss is induced by estrogen depletion in vivo specifically in females [176]. These discrepant findings are explained by a sex-specific link between 
hippocampal plasticity and the concentration of circulating hormones.

Brain-derived neurotrophic factor (BDNF), one of the key molecules modulating brain plasticity, induces longlasting potentiation of synapses during specific learning and memory processes [177]. BDNF interacts with the major metabolite of T, 17 $\beta$-estradiol, in mossy fibers during normal hippocampal function [178]. Transcripts of BDNF and two CaMKKb-regulated genes are upregulated in wild-type male, but not female mice, after contextual fear conditioning $[179,180]$. In mossy fibers, $17 \beta$-estradiol upregulates BDNF synthesis in adult female rats, whereas $\mathrm{T}$ impairs BDNF expression via tonic suppression in adult male rats [181]. Strong excitability associated with high levels of BDNF in mossy fibers in females may facilitate the normal functioning of the CA3 area. The role of interactions between androgens and BDNF in the maintenance of neuronal populations and plasticity has been acknowledged in several sexually dimorphic nuclei in various animal models [182]. Therefore, the sex-specific regulation of BDNF expression strongly suggests that the sexes use distinct forms of synaptic plasticity (for example, mediated by different molecular actors) during contextual memory formation [183].

The effects of stress on hippocampal neurogenesis and synaptogenesis are also sexually dimorphic. Chronic restraint stress produces atrophy of the dendritic tree of CA3 neurons, exclusively in the apical field in males and only in the basal field in females [184]. Chronic stress impairs cell proliferation and survival [185] and strengthens presynaptic inputs in males [186], whereas the inverse pattern occurs in females. Chronic stress in early life has lasting consequences on hippocampal structure and function in mice and suggests that male mice are more susceptible than females to early stress [187]. Therefore, it seems that males and females use distinct molecular mechanisms to learn from the same tasks. Alternatively, sex-dependent strategies in the same learning situation may activate distinct molecular processes $[188,189]$ and result in superior experience-dependent structural modifications in males [190,191].

\section{Sex differences of regional brain plasticity after brain damage in adulthood}

Females are protected against stroke and its inflammatory effects both at a young age and post-menopause, when sex differences in circulating hormones are minimal [192]. However, women seem to be at a disadvantage in particular conditions where brain repair or reorganization is an important component of post-acute phase recovery, such as stress response plasticity, the pre-clinical phase of Alzheimer's disease [193], functional recovery after trauma or ischemic stroke [194], and multiple sclerosis $[195,196]$. In these conditions, the outcome of female patients is worse than that of male patients.

\section{Ischemic stroke and NOS1}

Nitric oxide synthase-1 (NOS1) is an enzyme involved in several forms of plasticity including hippocampaldependent learning and memory, experience-dependent plasticity in the barrel cortex, and LTP in the hippocampus and neocortex. LTP is absent in male but not female $\alpha$ NOS1 knockout mice, indicating that residual LTP in females is not nitric oxide-dependent. Experiencedependent potentiation resulting from single-whisker experience (removal of all but one whisker from one side of the face) is significantly impaired in male $\alpha$ NOS1 knockout mice but does not affect females, suggesting that cortical plasticity relies more on NOS in males than in females. Therefore, synaptic neocortical plasticity mechanisms differ between males and females, including both basic plasticity induction pathways and the ability of plasticity mechanisms to compensate for the loss of $\alpha$ NOS1 [197].

\section{Mild traumatic brain injury}

Sex differences in the functional outcome of traumatic brain injury (TBI) have long been recognized [198]. In animals, females exhibit lower TBI-related mortality, morbidity, and behavioral deficits than males [199,200]. According to the gonadal steroid hypothesis, gonadal hormones, such as progesterone, confer a prophylactic effect, thus limiting the severity of injuries and facilitating recovery in females [201]. However, the role of biological sex in human TBI is less clear, with conflicting reports regarding mortality and morbidity [202,203]. Mild TBI and sport-related concussion in particular provide a better model than severe TBI to understand the influence of sex on TBI outcome. Females exhibit postconcussion syndrome more frequently than men [198] and take longer to return to school/work following injury [204]. Furthermore, sport studies report that TBI cognitive performance is poorer in women than in men $[205,206]$ and show that women more frequently experience concussion-related symptoms [206].

Studies examining concussive injuries of various origins have identified hormone disruption as a key factor underlying sex differences in the outcome of concussion $[198,207]$. One-month post injury, women taking birth control report fewer neuropsychological and neuropsychiatric symptoms than other women and men [198]. In addition, women injured during the luteal phase of menses report more somatic symptoms and a lower quality of life than those injured during the follicular phase or on birth control [208]. However, not all studies conclude that men have a more favorable outcome than women following concussion [209,210]. Nonetheless, 
most studies indicate that women exhibit poorer outcomes than men and implicate hormonal disruption as a key factor accounting for sex-related differences in TBI outcomes.

\section{Multiple sclerosis}

Multiple sclerosis (MS) involves the destruction of the nerve cover in brain and spinal cord white matter, developing either continuously without remission or to complete remission interspersed with successive attacks. Compensatory plasticity plays a major role in clinical relapses in MS. The sex ratio favoring women has been increasing from $2: 1$ to $3: 1$ in the past few decades [196].

Compensatory plasticity in MS can involve regional rededication (for example, the hyper-activation of alternative regions during the active phases of MS) or microstructural modification (for example, modifications of synaptic strength in intact regions). MS patients with a lateralized motor deficit display high ipsilateral and contra-lateral activity in cortical motor areas, which are less activated or not activated at all in control individuals. The enhancement of activity in cortical motor regions is correlated with brain damage [211,212] and can be seen from the amplitude of low frequency resting state activity [213]. This pattern is partially reversible during the remission phase. Strong LTP in MS patients demonstrates the plastic adaptation of intact neurons. In patients undergoing remission, platelet-derived growth factor (PDGF) is associated with strong LTP and high regional compensation. By contrast, in MS patients not undergoing remission or in those with progressive MS, strong LTP is not detected in intact regions [214,215]. A protective effect of physiological $\mathrm{T}$ may be responsible, at least in part, for the low susceptibility of men to MS [196]. However, animal models enabling the effects of sex hormones and chromosomes to be studied separately indicate that genetic sex plays a major role. For instance, genes on the Y chromosome have a protective effect in EAE, an animal model of MS [216].

The relationship between sex differences in functional compensation in adults and during early developmental cortical reallocation remains to be established. Nonetheless, differences in tissue repair support the idea that women are at a disadvantage regarding their plastic reaction to brain injury, as a result of combined genetic and hormonal effects [165]. This may be consistent with preliminary histological findings reporting a larger number of synapses in the temporal neocortex of epileptic male adults with mesial temporal lobe epilepsy (secondary to hippocampal alterations), than in females with the same condition. Although this evidence is indirect and requires further validation, these observations suggest the existence of sex differences in brain plasticity indicative of a low general level of plasticity in females, which may interfere with early cortical reallocations involved in autism.

\section{Conclusions}

Recent studies investigating sex-differences in autism have attempted to distinguish sex differences in diagnosis and phenotype from the search for 'general models of etiology and etiological-developmental mechanisms' [217]. With this in mind, we searched for a possible link between enhanced perceptual functioning and the biased sex ratio in autism. We examined studies investigating sex differences in the brain transcriptome, brain imaging data, brain plasticity following trauma or disease in nonautistic individuals, and the association of these differences with comparable common features of AS.

Genetic, transcriptomic, and animal model studies demonstrate the central role of brain plasticity in autism because many mutations involved in AS affect synaptic structure, function, and plasticity. In addition, indirect but nonetheless strong arguments from animal models, brain imaging, development, and studies of the brain transcriptome and plasticity in adulthood suggest that an enhanced plastic reaction is involved in the sex ratio bias in autism. The protective effect of the female sex against these mutations and the presence of sexual dimorphism in pathways involved in synaptic plasticity support the idea that: 1) a similar genetic event may trigger a different plastic reaction in males and females; and 2) plasticity is more likely to be disrupted in males than in females. Other indirect evidence comes from adult sex differences in reconstructive and compensatory brain plasticity.

A review of studies examining sexual dimorphism from brain imaging data of non-autistic and autistic individuals indicates that regions displaying functional, structural, and connectivity enhancements overlap with those in the perceptual (mostly visual) associative cortex that is more connected in males than in females. This convergence, observed in the mature brain, may originate from sexually dimorphic changes occurring during prenatal and early postnatal brain development because gene expression and hormone secretion are highly dependent on biological sex during these periods.

As a new basis for the understanding of sex ratio bias in autism, we now hypothesize that autistic phenotypes result from plastic reactions involving the most plastic, sexually dimorphic brain regions, in individuals whose threshold for this reaction is lowered by genetic or environmental causes. A severe mutation targeting essential synaptic structures may impair synapse formation and trigger a compensatory, abnormal plastic reaction in individuals with a low threshold. In this situation, highly penetrant mutations would cause a monogenic, syndromic phenotype with low IQ whereby the mutated 
genes are also expressed in other cells and tissues. When less severe mutations occur, the cognitive function of the individual is mainly preserved, while the mutation triggers a mostly typical, but disproportional, plastic reaction. In this paper, we reviewed the arguments indicating that such an occurrence is more likely in males than in females because males have a lower threshold for plastic reactions. The fact that autismrelated differences continue to develop throughout life suggests that sexually dimorphic regional plasticity, evident in non-autistic individuals, plays a role in the developmental transformation of the autistic brain. This chain of events applies to autistic individuals with a high IQ, who are disproportionately male, and thus accounts for male-bias in the autistic sex ratio. It also predicts that sex differences in the autistic phenotype are constrained by topographical, chronological, and systemic differences in plasticity.

\section{Future directions}

So far, the explanation for the bias in the autistic sex ratio has been limited to hormone-dependent effects and the questionable similarities between the strong performance of males in some cognitive tasks and autistic talents and PP. The investigation of sex differences involving genetic, non-hormonal sex-dependent mechanisms, microstructural experience-dependent plasticity, and importantly, reallocation rules, is clearly a new research avenue, which will extend our understanding of sex bias in autism to factors beyond the hormonal effects documented by the EBM model (Table 1). One of the main assumptions of the hypothesis is that plastic reallocation, even outside the period of hormonal influence, differs according to sex. Thus, it will be important to search for sex differences in functional reallocation following early sensory impairment in non-autistic individuals, as of yet uncharted territory. Another avenue, which may document the "threshold" component of the TTT model is the search for sex ratio or phenotypic sex differences in the most frequent mutations associated with syndromic autism, especially those linked to strong plasticity as documented in animal models.

Synaptic plasticity is the most basic mechanism and best studied form of brain plasticity. Regional plasticity probably involves several molecular plasticity mechanisms at different levels (synaptic, neuronal, regional, and circuitry) and in various forms (functional and structural plasticity). Brain imaging studies have indicated that the changes in AS individuals, in particular those without ID, are regional and compatible with plastic reactions; however, it remains to be demonstrated whether these two levels of enhanced synaptic and regional plasticity are associated in the same person and whether they differ in males and females.
Finally, studies assessing domain-specific strengths in women may determine the targets of sex-specific experience-dependent plasticity.

\section{Abbreviations}

AS: autism spectrum; BDNF: brain-derived neurotrophic factor; CaMKK: Ca2 +/calmodulin kinase; CNV: copy number variants; CREB: CAMP response element-binding protein; DN: de novo; DTI: diffusion tensor imaging; EEG: electro-encephalography; EMB: extreme male brain; FMRP: fragile $X$ mental retardation protein; $\mathrm{fT}$ : fetal testosterone; FXS: fragile X syndrome; ID: intellectual disability; IQ: intellectual quotient; KO: knock-out; LGD: likely gene disruptive; LTD: long-term depression; LTP: long-term potentiation; mRNA: messenger RNA; MS: multiple sclerosis; NOS1: nitric oxide synthase-1; NPC: neural progenitor cells; PDGF: platelet-derived growth factor; PP: perceptual peak; PSD: post-synaptic density; RNA: ribonucleic acid; siRNA: small-interfering RNA; RRBI: repetitive, restrictive behaviors and interests; SIS: special isolated skill; SNV: single nucleotide variants; SP: synaptic plasticity; T: testosterone; TBI: traumatic brain injury; TD: typically developing; TTT: trigger-threshold-target; VPA: valproic acid; WES: whole exome sequencing.

\section{Competing interests}

The authors declare they have no competing interest.

\section{Authors' contributions}

LM, PD and LX contributed identically to this paper. LM elaborated the working hypothesis, initiated and co-coordinated the writing of the manuscript, and wrote the introduction, the conclusion and the section on multiple sclerosis. PD wrote the section on brain imaging, the section on hormonal effects, the introduction, the conclusion and co-coordinated the entire manuscript. LX wrote the genetic section and co-coordinated the entire manuscript. SJ and BFDA gave feedback on the manuscript at each stage of its elaboration, SM contributed to the rationale and RM wrote the section on TBI. All authors read and approved the manuscript.

\section{Acknowledgements}

The authors would like to thank Christiane Belleville for clerical support and Alex Edelman and associates for editing the English version of the manuscript. This work was supported by a grant from the Canadian Institute for Health Research (CIHR) Perception - language relationships in autism, MOP-130277, awarded to LM.

\section{Author details}

${ }^{1}$ Centre d'excellence en Troubles envahissants du dévelopement de I'Université de Montréal (CETEDUM), Montréal, Canada. ${ }^{2}$ Hôpital Rivière-des-Prairies, Département de Psychiatrie, Montréal, Canada. ${ }^{3}$ Centre de Recherche de I'Institut Universitaire en Santé Mentale de Montréal, Québec, Canada. ${ }^{4}$ Department of Psychiatry, University of Montreal, Québec, Canada. ${ }^{5}$ Département de Biologie, École Normale Supérieure de Lyon, Lyon CEDEX 07, France. ${ }^{6}$ Institute of Clinical Radiology, University Hospitals,

Munich, Germany. ${ }^{7}$ Athinoula A. Martinos Center for Biomedical Imaging, Department of Radiology, Massachusetts General Hospital, Charlestown, MA 02129, USA. ${ }^{8}$ Harvard University, Center for Brain Science, Cambridge, MA 02138, USA. 'Department of Health Sciences, University of Montreal, Montreal, Canada. ${ }^{10}$ College of Applied Health Sciences, University of Illinois, Urbana-Champaign, USA. ${ }^{11}$ Centre de recherche, Centre Hospitalier Universitaire Sainte Justine, Montréal, Canada. ${ }^{12}$ Service of Medical Genetics, University Hospital of Lausanne, University of Lausanne, Lausanne 1011, Switzerland.

Received: 26 December 2014 Accepted: 27 April 2015 Published online: 05 June 2015

\section{References}

1. Fombonne E. Epidemiology of pervasive developmental disorders. Pediatr Res. 2009;65:591-8.

2. Werling DM, Geschwind DH. Understanding sex bias in autism spectrum disorder. Proc Natl Acad Sci U S A. 2013;110:4868-9.

3. Jacquemont $\mathrm{S}$, Coe BP, Hersch M, Duyzend MH, Krumm N, Bergmann S, et al. A higher mutational burden in females supports a "female protective model" 
in neurodevelopmental disorders. Am J Hum Genet. 2014;94(3):415-25. doi:10.1016/j.ajhg.2014.02.001.

4. Betancur C. Etiological heterogeneity in autism spectrum disorders: more than 100 genetic and genomic disorders and still counting. Brain Res. 2011;1380:42-77.

5. Lim ET, Raychaudhuri S, Sanders SJ, Stevens C, Sabo A, MacArthur DG, et al. Rare complete knockouts in humans: population distribution and significant role in autism spectrum disorders. Neuron. 2013;77:235-42.

6. Stein $J$, Parikshak NN, Geschwind DH. Rare inherited variation in autism: beginning to see the forest and a few trees. Neuron. 2013;77:209-11.

7. Baron-Cohen S, Lombardo MV, Auyeung B, Ashwin E, Chakrabarti B, Knickmeyer R. Why are autism spectrum conditions more prevalent in males? PLoS Biol. 2011;9:e1001081.

8. Mottron L. Changing perceptions: the power of autism. Nature. 2011:479:33-5.

9. Collignon O, Lassonde M, Lepore F, Bastien D, Veraart C. Functional cerebral reorganization for auditory spatial processing and auditory substitution of vision in early blind subjects. Cereb Cortex. 2007;17:457-65.

10. Mottron L, Bouvet L, Bonnel A, Samson F, Burack JA, Dawson M, et al. Veridical mapping in the development of exceptional autistic abilities. Neurosci Biobehav Rev. 2013;37:209-28.

11. Meilleur AA, Berthiaume C, Bertone A, Mottron L. Autism-specific covariation in perceptual performances: "g" or "p" factor? PLoS One. 2014;9:e103781.

12. Meilleur AA, Jelenic $P$, Mottron $L$. Prevalence of clinically and empirically defined talents and strengths in autism. J Autism Dev Disord. 2015;45(5):1354-67. doi:10.1007/s10803-014-2296-2.

13. Poulin-Lord MP, Barbeau EB, Soulières I, Monchi O, Doyon J, Benali $\mathrm{H}$, et al. Increased topographical variability of task-related activation in perceptive and motor associative regions in adult autistics. Neuroimage Clin. 2014;4:444-53.

14. Byrge L, Dubois J, Tyszka JM, Adolphs R, Kennedy DP. Idiosyncratic brain activation patterns are associated with poor social comprehension in autism. J Neurosci. 2015;35:5837-50.

15. Hahamy A, Behrmann M, Malach R. The idiosyncratic brain: distortion of spontaneous connectivity patterns in autism spectrum disorder. Nat Neurosci. 2015;18:302-9.

16. Samson F, Mottron L, Soulières I, Zeffiro TA. Enhanced visual functioning in autism: an ALE meta-analysis. Hum Brain Mapp. 2012;33(7):1553-81. doi:10.1002/hbm.21307.

17. Mueller S, Wang D, Fox MD, Yeo BT, Sepulcre J, Sabuncu MR, et al. Individual variability in functional connectivity architecture of the human brain. Neuron. 2013;77:586-95.

18. Samson F, Benali H, Doyon J, Zeffiro TA, Mottron L: Speech acquisition predicts regions of enhanced cortical response to auditory stimulation in autism spectrum individuals. Psychiatry Research.

19. Mottron L, Dawson M, Soulieres I, Hubert B, Burack J. Enhanced perceptual functioning in autism: an update, and eight principles of autistic perception. J Autism Dev Disord. 2006;36:27-43.

20. Mottron L, Belleville S, Rouleau GA, Collignon O. Linking neocortical, cognitive, and genetic variability in autism with alterations of brain plasticity: the Trigger-Threshold-Target model. Neurosci Biobehav Rev. 2014:47C:735-52.

21. Kelleher RJ, Bear MF. The autistic neuron: troubled translation? Cell. 2008;135:401-6.

22. Baudouin SJ, Gaudias J, Gerharz S, Hatstatt L, Zhou K, Punnakkal P, et al. Shared synaptic pathophysiology in syndromic and nonsyndromic rodent models of autism. Science. 2012:338:128-32

23. Isshiki M, Tanaka S, Kuriu T, Tabuchi K, Takumi T, Okabe S. Enhanced synapse remodelling as a common phenotype in mouse models of autism Nat Commun. 2014;5:4742.

24. Toro R, Konyukh M, Delorme R, Leblond C, Chaste P, Fauchereau F, et al. Key role for gene dosage and synaptic homeostasis in autism spectrum disorders. Trends Genet. 2010;26:363-72.

25. Zhao X, Leotta A, Kustanovich V, Lajonchere C, Geschwind DH, Law K, et al. A unified genetic theory for sporadic and inherited autism. Proc Natl Acad Sci U S A. 2007:104:12831-6.

26. O'Roak BJ, Deriziotis P, Lee C, Vives L, Schwartz JJ, Girirajan S, et al. Exome sequencing in sporadic autism spectrum disorders identifies severe de novo mutations. Nat Genet. 2011;43:585-9.

27. Chahrour MH, Yu TW, Lim ET, Ataman B, Coulter ME, Hill RS, et al. Whole-exome sequencing and homozygosity analysis implicate depolarization-regulated neuronal genes in autism. PLoS Genet. 2012:8:e1002635

28. O'Roak BJ, Vives L, Girirajan S, Karakoc E, Krumm N, Coe BP, et al. Sporadic autism exomes reveal a highly interconnected protein network of de novo mutations. Nature. 2012;485:246-50.

29. Sanders SJ, Murtha MT, Gupta AR, Murdoch JD, Raubeson MJ, Willsey AJ, et al. De novo mutations revealed by whole-exome sequencing are strongly associated with autism. Nature. 2012;485:237-41.

30. Yu TW, Chahrour MH, Coulter ME, Jiralerspong S, Okamura-lkeda K, Ataman $B$, et al. Using whole-exome sequencing to identify inherited causes of autism. Neuron. 2013;77:259-73.

31. De Rubeis S, He X, Goldberg AP, Poultney CS, Samocha K, Ercument Cicek A, et al. Synaptic, transcriptional and chromatin genes disrupted in autism. Nature. 2014;515:209-15.

32. Iossifov I, O'Roak BJ, Sanders SJ, Ronemus M, Krumm N, Levy D, et al. The contribution of de novo coding mutations to autism spectrum disorder. Nature. 2014;515:216-21.

33. Iossifov I, Ronemus M, Levy D, Wang Z, Hakker I, Rosenbaum J, et al. De novo gene disruptions in children on the autistic spectrum. Neuron. 2012;74:285-99.

34. Hormozdiari F, Penn O, Borenstein E, Eichler EE. The discovery of integrated gene networks for autism and related disorders. Genome Res. 2015;25(1):142-54. doi:10.1101/gr.178855.114

35. Liu L, Lei J, Sanders SJ, Willsey AJ, Kou Y, Cicek AE, et al. DAWN: a framework to identify autism genes and subnetworks using gene expression and genetics. Mol Autism. 2014;5:22.

36. Willsey AJ, Sanders SJ, Li M, Dong S, Tebbenkamp AT, Muhle RA, et al. Coexpression networks implicate human midfetal deep cortical projection neurons in the pathogenesis of autism. Cell. 2013;155:997-1007.

37. Parikshak NN, Luo R, Zhang A, Won H, Lowe JK, Chandran V, et al. Integrative functional genomic analyses implicate specific molecular pathways and circuits in autism. Cell. 2013;155:1008-21.

38. Ben-David E, Shifman S. Networks of neuronal genes affected by common and rare variants in autism spectrum disorders. PLoS Genet. 2012:8:e1002556.

39. Ben-David E, Shifman S. Combined analysis of exome sequencing points toward a major role for transcription regulation during brain development in autism. Mol Psychiatry. 2013;18:1054-6.

40. Darnell JC, Van Driesche SJ, Zhang C, Hung KY, Mele A, Fraser CE, et al. FMRP stalls ribosomal translocation on mRNAs linked to synaptic function and autism. Cell. 2011;146:247-61.

41. Bayes A, van de Lagemaat LN, Collins MO, Croning MD, Whittle IR, Choudhary JS, et al. Characterization of the proteome, diseases and evolution of the human postsynaptic density. Nat Neurosci. 2011;14:19-21.

42. Voineagu I, Wang $X$, Johnston P, Lowe JK, Tian $Y$, Horvath S, et al. Transcriptomic analysis of autistic brain reveals convergent molecular pathology. Nature. 2011;474:380-4.

43. Kang HJ, Kawasawa Yl, Cheng F, Zhu Y, Xu X, Li M, et al. Spatio-temporal transcriptome of the human brain. Nature. 2011;478:483-9.

44. Blake JA, Bult CJ, Kadin JA, Richardson JE, Eppig JT, Mouse Genome Database G. The Mouse Genome Database (MGD): premier model organism resource for mammalian genomics and genetics. Nucleic Acids Res. 2011;39:D842-8.

45. Jamain S, Quach H, Betancur C, Råstam M, Colineaux C, Gillberg IC, et al. Mutations of the $X$-linked genes encoding neuroligins NLGN3 and NLGN4 are associated with autism. Nat Genet. 2003:34:27-9.

46. Laumonnier F, Bonnet-Brilhault F, Gomot M, Blanc R, David A, Moizard MP, et al. X-linked mental retardation and autism are associated with a mutation in the NLGN4 gene, a member of the neuroligin family. Am J Hum Genet. 2004;74:552-7.

47. Chanda S, Aoto J, Lee SJ, Wernig M, Südhof TC. Pathogenic mechanism of an autism-associated neuroligin mutation involves altered AMPA-receptor trafficking. Mol Psychiatry. 2015 Mar 17. doi:10.1038/mp.2015.20. PubMed PMID: 25778475

48. Craig AM, Kang Y. Neurexin-neuroligin signaling in synapse development. Curr Opin Neurobiol. 2007;17:43-52.

49. Matsukawa H, Akiyoshi-Nishimura S, Zhang Q, Luján R, Yamaguchi K, Goto $\mathrm{H}$, et al. Netrin-G/NGL complexes encode functional synaptic diversification. J Neurosci. 2014;34:15779-92.

50. Delattre V, La Mendola D, Meystre J, Markram H, Markram K. Nlgn4 knockout induces network hypo-excitability in juvenile mouse somatosensory cortex in vitro. Sci Rep. 2013;3:2897. 
51. Weickert CS, Elashoff M, Richards AB, Sinclair D, Bahn S, Paabo S, et al. Transcriptome analysis of male-female differences in prefrontal cortical development. Mol Psychiatry. 2009;14:558-61.

52. Yoshida K, Sugano S. Identification of a novel protocadherin gene (PCDH11) on the human XY homology region in Xq21.3. Genomics. 1999;62:540-3.

53. Blanco $P$, Sargent CA, Boucher CA, Mitchell M, Affara NA. Conservation of PCDHX in mammals; expression of human X/Y genes predominantly in brain. Mamm Genome. 2000:11:906-14.

54. Blanco-Arias $P$, Sargent $C A$, Affara NA. Protocadherin $X(P C D H X)$ and $Y$ (PCDHY) genes; multiple mRNA isoforms encoding variant signal peptides and cytoplasmic domains. Mamm Genome. 2004;15:41-52.

55. Lopes AM, Ross N, Close J, Dagnall A, Amorim A, Crow TJ. Inactivation status of PCDH11X: sexual dimorphisms in gene expression levels in brain. Hum Genet. 2006;119:267-75.

56. Veerappa AM, Saldanha M, Padakannaya P, Ramachandra NB. Genome-wide copy number scan identifies disruption of PCDH11X in developmental dyslexia. Am J Med Genet B Neuropsychiatr Genet. 2013;162B:889-97.

57. Speevak MD, Farrell SA. Non-syndromic language delay in a child with disruption in the Protocadherin11X/Y gene pair. Am J Med Genet B Neuropsychiatr Genet. 2011;156B:484-9.

58. Ronald A, Hoekstra RA. Autism spectrum disorders and autistic traits: a decade of new twin studies. Am J Med Genet B Neuropsychiatr Genet. 2011;156B:255-74

59. Ronald A, Larsson $H$, Anckarsater $H$, Lichtenstein P. A twin study of autism symptoms in Sweden. Mol Psychiatry. 2011;16:1039-47.

60. Robinson EB, Lichtenstein P, Anckarsater H, Happe F, Ronald A. Examining and interpreting the female protective effect against autistic behavior. Proc Natl Acad Sci U S A. 2013;110:5258-62.

61. Sebat J, Lakshmi B, Malhotra D, Troge J, Lese-Martin C, Walsh T, et al. Strong association of de novo copy number mutations with autism. Science. 2007;316:445-9.

62. Levy D, Ronemus M, Yamrom B, Lee YH, Leotta A, Kendall J, et al. Rare de novo and transmitted copy-number variation in autistic spectrum disorders. Neuron. 2011;70:886-97.

63. Sanders SJ, Ercan Sencicek AG, Hus V, Luo R, Murtha MT, Moreno De Luca $D$, et al. Multiple recurrent de novo CNVs, including duplications of the 7q11.23 Williams syndrome region, are strongly associated with autism. Neuron. 2011;70:863-85.

64. Sato D, Lionel AC, Leblond CS, Prasad A, Pinto D, Walker S, et al. SHANK1 deletions in males with autism spectrum disorder. Am J Hum Genet. 2012;90:879-87.

65. Pinto D, Delaby E, Merico D, Barbosa M, Merikangas A, Klei L, et al. Convergence of genes and cellular pathways dysregulated in autism spectrum disorders. Am J Hum Genet. 2014;94:677-94.

66. Jacquemont S, Coe BP, Hersch M, Duyzend MH, Krumm N, Bergmann S, et al. A higher mutational burden in females supports a "female protective model" in neurodevelopmental disorders. Am J Hum Genet. 2014;94:415-25.

67. Honda H, Shimizu Y, Imai M, Nitto Y. Cumulative incidence of childhood autism: a total population study of better accuracy and precision. Dev Med Child Neurol. 2005:47:10-8.

68. Berkel S, Marshall CR, Weiss B, Howe J, Roeth R, Moog U, et al. Mutations in the SHANK2 synaptic scaffolding gene in autism spectrum disorder and mental retardation. Nat Genet. 2010;42:489-91.

69. Fenlon LR, Liu S, Gobius I, Kurniawan ND, Murphy S, Moldrich RX, et al. Formation of functional areas in the cerebral cortex is disrupted in a mouse model of autism spectrum disorder. Neural Dev. 2015;10(1):10. doi:10.1186/s13064-015-0033-y.

70. Penagarikano O, Mulle JG, Warren ST. The pathophysiology of fragile $x$ syndrome. Annu Rev Genomics Hum Genet. 2007:8:109-29.

71. Bassell GJ, Warren ST. Fragile X syndrome: loss of local mRNA regulation alters synaptic development and function. Neuron. 2008;60:201-14.

72. Antar LN, Bassell GJ. Sunrise at the synapse: the FMRP mRNP shaping the synaptic interface. Neuron. 2003;37:555-8.

73. Huber KM, Gallagher SM, Warren ST, Bear MF. Altered synaptic plasticity in a mouse model of fragile X mental retardation. Proc Natl Acad Sci U S A. 2002:99:7746-50.

74. Koekkoek SK, Yamaguchi K, Milojkovic BA, Dortland BR, Ruigrok TJ, Maex R, et al. Deletion of FMR1 in Purkinje cells enhances parallel fiber LTD, enlarges spines, and attenuates cerebellar eyelid conditioning in fragile $X$ syndrome. Neuron. 2005:47:339-52.

75. Li J, Pelletier MR, Perez Velazquez JL, Carlen PL. Reduced cortical synaptic plasticity and GluR1 expression associated with fragile $X$ mental retardation protein deficiency. Mol Cell Neurosci. 2002;19:138-51.
76. Lugli G, Larson J, Martone ME, Jones Y, Smalheiser NR. Dicer and elF2c are enriched at postsynaptic densities in adult mouse brain and are modified by neuronal activity in a calpain-dependent manner. J Neurochem. 2005:94:896-905.

77. Zhao MG, Toyoda H, Ko SW, Ding HK, Wu LJ, Zhuo M. Deficits in trace fear memory and long-term potentiation in a mouse model for fragile $X$ syndrome. J Neurosci. 2005;25:7385-92.

78. Desai NS, Casimiro TM, Gruber SM, Vanderklish PW. Early postnatal plasticity in neocortex of Fmr1 knockout mice. J Neurophysiol. 2006;96:1734-45.

79. Wilson BM, Cox CL. Absence of metabotropic glutamate receptor-mediated plasticity in the neocortex of fragile X mice. Proc Natl Acad Sci U S A. 2007:104:2454-9.

80. Giraldez-Perez RM, Avila MN, Feijoo-Cuaresma M, Heredia R, De Diego-Otero $Y$, Real MA, et al. Males but not females show differences in calbindin immunoreactivity in the dorsal thalamus of the mouse model of fragile $X$ syndrome. J Comp Neurol. 2013;521:894-911.

81. Leblond CS, Nava C, Polge A, Gauthier J, Huguet G, Lumbroso S, et al. Meta-analysis of SHANK mutations in autism spectrum disorders: a gradient of severity in cognitive impairments. PLoS Genet. 2014;10:e1004580.

82. Hung AY, Futai K, Sala C, Valtschanoff JG, Ryu J, Woodworth MA, et al. Smaller dendritic spines, weaker synaptic transmission, but enhanced spatial learning in mice lacking Shank1. J Neurosci. 2008;28:1697-708.

83. Hung AY, Sung CC, Brito IL, Sheng M. Degradation of postsynaptic scaffold GKAP and regulation of dendritic spine morphology by the TRIM3 ubiquitin ligase in rat hippocampal neurons. PLoS One. 2010:5:e9842.

84. Schmeisser MJ, Ey E, Wegener S, Bockmann J, Stempel AV, Kuebler A, et al. Autistic-like behaviours and hyperactivity in mice lacking ProSAP1/Shank2. Nature. 2012:486:256-60

85. Peca J, Feliciano C, Ting JT, Wang W, Wells MF, Venkatraman TN, et al. Shank3 mutant mice display autistic-like behaviours and striatal dysfunction. Nature. 2011;472:437-42.

86. Narita N, Kato M, Tazoe M, Miyazaki K, Narita M, Okado N. Increased monoamine concentration in the brain and blood of fetal thalidomide- and valproic acid-exposed rat: putative animal models for autism. Pediatr Res. 2002;52:576-9.

87. Markram H, Rinaldi T, Markram K. The intense world syndrome - an alternative hypothesis for autism. Front Neurosci. 2007;1:77-96.

88. Markram K, Markram H. The intense world theory - a unifying theory of the neurobiology of autism. Front Hum Neurosci. 2010;4:224.

89. Rinaldi T, Kulangara K, Antoniello K, Markram H. Elevated NMDA receptor levels and enhanced postsynaptic long-term potentiation induced by prenatal exposure to valproic acid. Proc Natl Acad Sci U S A. 2007;104:13501-6.

90. Rinaldi T, Perrodin C, Markram H. Hyper-connectivity and hyper-plasticity in the medial prefrontal cortex in the valproic acid animal model of autism. Front Neural Circuits. 2008;2:4.

91. Markram K, Rinaldi T, La Mendola D, Sandi C, Markram H. Abnormal fear conditioning and amygdala processing in an animal model of autism. Neuropsychopharmacology. 2008;33:901-12.

92. Rinaldi T, Silberberg G, Markram H. Hyperconnectivity of local neocortical microcircuitry induced by prenatal exposure to valproic acid. Cereb Cortex. 2008;18:763-70.

93. Mowery TM, Wilson SM, Kostylev PV, Dina B, Buchholz JB, Prieto AL, et al Embryological exposure to valproic acid disrupts morphology of the deep cerebellar nuclei in a sexually dimorphic way. Int J Dev Neurosci. 2014:40C:15-23

94. Schneider T, Roman A, Basta-Kaim A, Kubera M, Budziszewska B, Schneider $K$, et al. Gender-specific behavioral and immunological alterations in an animal model of autism induced by prenatal exposure to valproic acid. Psychoneuroendocrinology. 2008;33:728-40.

95. Go HS, Kim KC, Choi CS, Jeon SJ, Kwon KJ, Han SH, et al. Prenatal exposure to valproic acid increases the neural progenitor cell pool and induces macrocephaly in rat brain via a mechanism involving the GSK-3beta/beta-catenin pathway. Neuropharmacology. 2012;63:1028-41.

96. Kim KC, Kim P, Go HS, Choi CS, Park JH, Kim HJ, et al. Male-specific alteration in excitatory post-synaptic development and social interaction in pre-natal valproic acid exposure model of autism spectrum disorder. J Neurochem. 2013;124:832-43.

97. Kim KC, Choi CS, Kim JW, Han SH, Cheong JH, Ryu JH, Shin CY. MeCP2 Modulates Sex Differences in the Postsynaptic Development of the 
Valproate Animal Model of Autism. Mol Neurobiol. 2014 Nov 18. PMID 25404090.

98. Zoghbi HY. MeCP2 dysfunction in humans and mice. J Child Neurol. 2005;20:736-40.

99. Zilles K, Palomero-Gallagher N, Amunts K. Development of cortical folding during evolution and ontogeny. Trends Neurosci. 2013;36:275-84.

100. Kolb B, Mychasiuk R, Gibb R. Brain development, experience, and behavior. Pediatr Blood Cancer. 2014;61:1720-3.

101. Raznahan A, Shaw P, Lalonde F, Stockman M, Wallace GL, Greenstein D, et al. How does your cortex grow? J Neurosci. 2011;31:7174-7.

102. Li G, Wang L, Shi F, Lyall AE, Lin W, Gilmore JH, et al. Mapping longitudinal development of local cortical gyrification in infants from birth to 2 years of age. J Neurosci. 2014;34:4228-38.

103. Brun CC, Leporé N, Pennec X, Lee AD, Barysheva M, Madsen SK, et al. Mapping the regional influence of genetics on brain structure variability - a tensor-based morphometry study. Neuroimage. 2009;48:37-49.

104. Andersen SL. Trajectories of brain development: point of vulnerability or window of opportunity? Neurosci Biobehav Rev. 2003;27:3-18.

105. Mutlu AK, Schneider M, Debbané M, Badoud D, Eliez S, Schaer M. Sex differences in thickness, and folding developments throughout the cortex. Neuroimage. 2013;82:200-7.

106. Raznahan A, Lee $Y$, Stidd R, Long R, Greenstein D, Clasen L, et al. Longitudinally mapping the influence of sex and androgen signaling on the dynamics of human cortical maturation in adolescence. Proc Natl Acad Sci U S A. 2010;107:16988-93.

107. Luders E, Narr KL, Thompson PM, Rex DE, Jancke L, Steinmetz H, et al. Gender differences in cortical complexity. Nat Neurosci. 2004;7:799-800.

108. Luders E, Narr KL, Zaidel E, Thompson PM, Toga AW. Gender effects on callosal thickness in scaled and unscaled space. Neuroreport. 2006;17:1103-6.

109. Ruigrok AN, Salimi-Khorshidi G, Lai MC, Baron-Cohen S, Lombardo MV, Tait $\mathrm{RJ}$, et al. A meta-analysis of sex differences in human brain structure. Neurosci Biobehav Rev. 2014;39:34-50.

110. Liu F, Cao S, Liu J, Du Z, Guo Z, Ren C. Ultrasound measurement of the corpus callosum and neural development of premature infants. Neural Regen Res. 2013;8:2432-40.

111. Gong G, He Y, Evans AC. Brain connectivity: gender makes a difference. Neuroscientist. 2011;17:575-91.

112. Ingalhalikar M, Smith A, Parker D, Satterthwaite TD, Elliott MA, Ruparel K, et al. Sex differences in the structural connectome of the human brain. Proc Natl Acad Sci U S A. 2014;111:823-8.

113. Tomasi $D$, Volkow ND. Gender differences in brain functional connectivity density. Hum Brain Mapp. 2012;33:849-60.

114. Satterthwaite TD, Wolf DH, Roalf DR, Ruparel K, Erus G, Vandekar S, Gennatas ED, Elliott MA, Smith A, Hakonarson H, Verma R, Davatzikos C, Gur RE, Gur RC. Linked Sex Differences in Cognition and Functional Connectivity in Youth. Cereb Cortex. 2014 Apr 25. PubMed PMID: 24646613.

115. Dennis EL, Jahanshad N, McMahon KL, de Zubicaray GI, Martin NG, Hickie IB, et al. Development of brain structural connectivity between ages 12 and 30: a 4-Tesla diffusion imaging study in 439 adolescents and adults. Neuroimage. 2013;64:671-84.

116. Yan C, Gong G, Wang J, Wang D, Liu D, Zhu C, et al. Sex- and brain size-related small-world structural cortical networks in young adults: a DTI tractography study. Cereb Cortex. 2011;21:449-58.

117. Gong G, Rosa-Neto P, Carbonell F, Chen ZJ, He Y, Evans AC. Age- and gender-related differences in the cortical anatomical network. J Neurosci. 2009:29:15684-93.

118. Biswal BB, Mennes M, Zuo XN, Gohel S, Kelly C, Smith SM, et al. Toward discovery science of human brain function. Proc Natl Acad Sci U S A. 2010;107:4734-9

119. Kana RK, Uddin LQ, Kenet T, Chugani D, Müller RA. Brain connectivity in autism. Front Hum Neurosci. 2014;8:349.

120. Frith C. What do imaging studies tell us about the neural basis of autism? Novartis Found Symp. 2003;251:149-66. discussion 166-176, 281-197.

121. Just MA, Cherkassky VL, Keller TA, Minshew NJ. Cortical activation and synchronization during sentence comprehension in high-functioning autism: evidence of underconnectivity. Brain. 2004;127:1811-21.

122. Vissers ME, Cohen MX, Geurts HM. Brain connectivity and high functioning autism: a promising path of research that needs refined models, methodological convergence, and stronger behavioral links. Neurosci Biobehav Rev. 2012;36:604-25.
123. Courchesne $E$, Pierce $K$. Why the frontal cortex in autism might be talking only to itself: local over-connectivity but long-distance disconnection. Curr Opin Neurobiol. 2005;15:225-30.

124. Barttfeld P, Wicker B, Cukier S, Navarta S, Lew S, Sigman M. A big-world network in ASD: dynamical connectivity analysis reflects a deficit in long-range connections and an excess of short-range connections. Neuropsychologia. 2011:49:254-63.

125. Just MA, Keller TA, Malave VL, Kana RK, Varma S. Autism as a neural systems disorder: a theory of frontal-posterior underconnectivity. Neurosci Biobehav Rev. 2012;36:1292-313.

126. Müller RA. Anatomical and functional connectivity in autism spectrum disorders. In: Patel VB, Preedy VR, Martin CR, editors. Comprehensive guide to autism. New York, USA: Springer New York; 2014. p. 49-75.

127. Shi F, Wang L, Peng Z, Wee CY, Shen D. Altered modular organization of structural cortical networks in children with autism. PLoS One. 2013:8:e63131.

128. Zhou Y, Yu F, Duong T. Multiparametric MRI characterization and prediction in autism spectrum disorder using graph theory and machine learning. PLoS One. 2014;9:e90405.

129. Peters JM, Taquet M, Vega C, Jeste SS, Sanchez Fernandez I, Tan J, et al. Brain functional networks in syndromic and non-syndromic autism: a graph theoretical study of EEG connectivity. BMC Med. 2013;11:54.

130. Maximo JO, Cadena EJ, Kana RK. The implications of brain connectivity in the neuropsychology of autism. Neuropsychol Rev. 2014;24:16-31.

131. Keehn B, Shih P, Brenner LA, Townsend J, Müller RA. Functional connectivity for an "island of sparing" in autism spectrum disorder: an fMRI study of visual search. Hum Brain Mapp. 2013;34:2524-37.

132. Turner KC, Frost L, Linsenbardt D, Mcllroy JR, Müller RA. Atypically diffuse functional connectivity between caudate nuclei and cerebral cortex in autism. Behav Brain Funct. 2006;2:34.

133. Noonan SK, Haist F, Müller RA. Aberrant functional connectivity in autism: evidence from low-frequency BOLD signal fluctuations. Brain Res. 2009;1262:48-63.

134. Keown CL, Shih P, Nair A, Peterson N, Mulvey ME, Müller RA. Local functional overconnectivity in posterior brain regions is associated with symptom severity in autism spectrum disorders. Cell Rep. 2013;5:567-72.

135. Leveille C, Barbeau EB, Bolduc C, Limoges E, Berthiaume C, Chevrier E, et al. Enhanced connectivity between visual cortex and other regions of the brain in autism: a REM sleep EEG coherence study. Autism Res. 2010;3:280-5.

136. Domínguez LG, Velázquez JL, Galán RF. A model of functional brain connectivity and background noise as a biomarker for cognitive phenotypes: application to autism. PLoS One. 2013;8:e61493.

137. Kikuchi M, Yoshimura Y, Shitamichi K, Ueno S, Hirosawa T, Munesue T, et al. A custom magnetoencephalography device reveals brain connectivity and high reading/decoding ability in children with autism. Sci Rep. 2013;3:1139.

138. Welchew DE, Ashwin C, Berkouk K, Salvador R, Suckling J, Baron-Cohen S, et al. Functional disconnectivity of the medial temporal lobe in Asperger's syndrome. Biol Psychiatry. 2005;57:991-8.

139. Barbeau EB, Lewis JD, Doyon J, Benali H, Zeffiro TA, Mottron L. A greater involvment of posterior brain areas in interhemispheric transfer in autism: fMRI, DTI and behavioral evidences. Neurolmage: Clinical.

140. Anderson JS, Druzgal TJ, Froehlich A, DuBray MB, Lange N, Alexander AL, et al. Decreased interhemispheric functional connectivity in autism. Cereb Cortex. 2011;21:1134-46.

141. Rudie JD, Brown JA, Beck-Pancer D, Hernandez LM, Dennis EL, Thompson PM, et al. Altered functional and structural brain network organization in autism. Neuroimage Clin. 2012;2:79-94.

142. Courchesne E, Campbell K, Solso S. Brain growth across the life span in autism: age-specific changes in anatomical pathology. Brain Res. 2011;1380:138-45.

143. Hazlett HC, Poe MD, Gerig G, Styner M, Chappell C, Smith RG, et al. Early brain overgrowth in autism associated with an increase in cortical surface area before age 2 years. Arch Gen Psychiatry. 2011;68:467-76.

144. Pierce K, Glatt SJ, Liptak GS, McIntyre LL. The power and promise of identifying autism early: insights from the search for clinical and biological markers. Ann Clin Psychiatry. 2009;21:132-47.

145. Zwaigenbaum L, Bryson S, Rogers T, Roberts W, Brian J, Szatmari P. Behavioral manifestations of autism in the first year of life. Int J Dev Neurosci. 2005;23:143-52.

146. Redcay E, Courchesne E. When is the brain enlarged in autism? A meta-analysis of all brain size reports. Biol Psychiatry. 2005;58:1-9. 
147. Courchesne E, Mouton PR, Calhoun ME, Semendeferi K, Ahrens-Barbeau C, Hallet MJ, et al. Neuron number and size in prefrontal cortex of children with autism. JAMA. 2011;306:2001-10.

148. Greimel E, Nehrkorn B, Schulte-Rüther M, Fink GR, Nickl-Jockschat T, Herpertz-Dahlmann B, et al. Changes in grey matter development in autism spectrum disorder. Brain Struct Funct. 2013;218:929-42.

149. Lange N, Travers BG, Bigler ED, Prigge MB, Froehlich AL, Nielsen JA, et al. Longitudinal volumetric brain changes in autism spectrum disorder ages 6-35 years. Autism Res. 2015;8(1):82-93. doi:10.1002/aur.1427.

150. Lai MC, Lombardo MV, Suckling J, Ruigrok AN, Chakrabarti B, Ecker C, et al. Biological sex affects the neurobiology of autism. Brain. 2013;136:2799-815.

151. Haar S, Berman S, Behrmann M, Dinstein I. Anatomical Abnormalities in Autism? Cereb Cortex. 2014 Oct 14. pii: bhu242. PubMed PMID:25316335.

152. Wallace GL, Robustelli B, Dankner N, Kenworthy L, Giedd JN, Martin A. Increased gyrification, but comparable surface area in adolescents with autism spectrum disorders. Brain. 2013;136:1956-67.

153. Nickl-Jockschat T, Habel U, Michel TM, Manning J, Laird AR, Fox PT, et al. Brain structure anomalies in autism spectrum disorder-a meta-analysis of VBM studies using anatomic likelihood estimation. Hum Brain Mapp. 2012;33:1470-89.

154. Cauda F, Costa T, Palermo S, D'Agata F, Diano M, Bianco F, et al. Concordance of white matter and gray matter abnormalities in autism spectrum disorders: a voxel-based meta-analysis study. Hum Brain Mapp. 2014;35(5):2073-98. doi:10.1002/hbm.22313.

155. Nordahl CW, Dierker D, Mostafavi I, Schumann CM, Rivera SM, Amaral DG, et al. Cortical folding abnormalities in autism revealed by surface-based morphometry. J Neurosci. 2007;27:11725-35.

156. Auzias G, Viellard M, Takerkart S, Villeneuve N, Poinso F, Fonséca DD, et al. Atypical sulcal anatomy in young children with autism spectrum disorder. Neuroimage Clin. 2014:4:593-603.

157. Collignon O, Champoux F, Voss P, Lepore F. Sensory rehabilitation in the plastic brain. Prog Brain Res. 2011;191:211-31.

158. Lord C, Schopler E, Revicki D. Sex differences in autism. J Autism Dev Disord. 1982;12:317-30

159. Szatmari P, Liu XQ, Goldberg J, Zwaigenbaum L, Paterson AD, Woodbury-Smith $M$, et al. Sex differences in repetitive stereotyped behaviors in autism: implications for genetic liability. Am J Med Genet B Neuropsychiatr Genet. 2012;159B:5-12.

160. Van Wijngaarden-Cremers PJ, van Eeten E, Groen WB, Van Deurzen PA, Oosterling IJ, Van der Gaag RJ. Gender and age differences in the core triad of impairments in autism spectrum disorders: a systematic review and meta-analysis. J Autism Dev Disord. 2014;44:627-35.

161. Hartley SL, Sikora DM. Sex differences in autism spectrum disorder: an examination of developmental functioning, autistic symptoms, and coexisting behavior problems in toddlers. J Autism Dev Disord. 2009;39:1715-22.

162. Lai MC, Lombardo MV, Pasco G, Ruigrok AN, Wheelwright SJ, Sadek SA, et al. A behavioral comparison of male and female adults with high functioning autism spectrum conditions. PLoS One. 2011;6:e20835.

163. Dworzynski K, Ronald A, Bolton P, Happé F. How different are girls and boys above and below the diagnostic threshold for autism spectrum disorders? J Am Acad Child Adolesc Psychiatry. 2012;51:788-97.

164. Gore AC, Martien KM, Gagnidze K, Pfaff D. Implications of prenatal steroid perturbations for neurodevelopment, behavior, and autism. Endocr Rev. 2014;35:961-91.

165. McCarthy MM, Arnold AP. Reframing sexual differentiation of the brain. Nat Neurosci. 2011;14:677-83.

166. Baron-Cohen S. The extreme male brain theory of autism. Trends Cogn Sci. 2002;6:248-54

167. Baron-Cohen S, Knickmeyer RC, Belmonte MK. Sex differences in the brain: implications for explaining autism. Science. 2005;310:819-23.

168. Baron-Cohen S, Auyeung B, Nørgaard-Pedersen B, Hougaard DM, Abdallah MW, Melgaard L, et al. Elevated fetal steroidogenic activity in autism. Mol Psychiatry. 2015;20(3):369-76. doi:10.1038/mp.2014.48

169. Pohl A, Cassidy S, Auyeung B, Baron-Cohen S. Uncovering steroidopathy in women with autism: a latent class analysis. Mol Autism. 2014;5:27.

170. Xu XJ, Zhang HF, Shou XJ, Li J, Jing WL, Zhou Y, et al. Prenatal hyperandrogenic environment induced autistic-like behavior in rat offspring. Physiol Behav. 2015:138:13-20.

171. Sarachana T, Xu M, Wu RC, Hu WW. Sex hormones in autism: androgens and estrogens differentially and reciprocally regulate RORA, a novel candidate gene for autism. PLoS One. 2011;6:e17116.
172. Sarachana T, Hu WW. Differential recruitment of coregulators to the RORA promoter adds another layer of complexity to gene (dys) regulation by sex hormones in autism. Mol Autism. 2013;4:39.

173. Trachtenberg JT, Chen BE, Knott GW, Feng G, Sanes JR, Welker E, et al. Long-term in vivo imaging of experience-dependent synaptic plasticity in adult cortex. Nature. 2002;420:788-94.

174. Yankova M, Hart SA, Woolley CS. Estrogen increases synaptic connectivity between single presynaptic inputs and multiple postsynaptic CA1 pyramidal cells: a serial electron-microscopic study. Proc Natl Acad Sci U S A. 2001;98:3525-30.

175. Harte-Hargrove LC, Maclusky NJ, Scharfman HE. Brain-derived neurotrophic factor-estrogen interactions in the hippocampal mossy fiber pathway: implications for normal brain function and disease. Neuroscience. 2013;239:46-66.

176. Fester L, Prange-Kiel J, Zhou L, Blittersdorf BV, Böhm J, Jarry H, et al. Estrogen-regulated synaptogenesis in the hippocampus: sexual dimorphism in vivo but not in vitro. J Steroid Biochem Mol Biol. 2012;131:24-9.

177. Tyler WJ, Perrett SP, Pozzo-Miller LD. The role of neurotrophins in neurotransmitter release. Neuroscientist. 2002;8:524-31.

178. Pluchino N, Russo M, Santoro AN, Litta P, Cela V, Genazzani AR. Steroid hormones and BDNF. Neuroscience. 2013;239:271-9.

179. Mizuno A, Villalobos ME, Davies MM, Dahl BC, Muller RA. Partially enhanced thalamocortical functional connectivity in autism. Brain Res. 2006;1104:160-74

180. Antunes-Martins A, Mizuno K, Irvine EE, Lepicard EM, Giese KP. Sex-dependent up-regulation of two splicing factors, Psf and Srp20, during hippocampal memory formation. Learn Mem. 2007;14:693-702.

181. Atwi S, McMahon D, Scharfman H, MacLusky NJ. Androgen Modulation of Hippocampal Structure and Function. Neuroscientist. 2014 Nov 21. pii: 1073858414558065. Review. PubMed PMID: 25416742.

182. Ottem EN, Bailey DJ, Jordan CL, Breedlove SM. With a little help from my friends: androgens tap BDNF signaling pathways to alter neural circuits. Neuroscience. 2013;239:124-38.

183. Mizuno K, Giese KP. Towards a molecular understanding of sex differences in memory formation. Trends Neurosci. 2010;33:285-91.

184. Galea LA, McEwen BS, Tanapat P, Deak T, Spencer RL, Dhabhar FS. Sex differences in dendritic atrophy of CA3 pyramidal neurons in response to chronic restraint stress. Neuroscience. 1997:81:689-97.

185. Westenbroek C, Den Boer JA, Veenhuis M, Ter Horst GJ. Chronic stress and social housing differentially affect neurogenesis in male and female rats. Brain Res Bull. 2004;64:303-8.

186. Carvalho-Netto EF, Myers B, Jones K, Solomon MB, Herman JP. Sex differences in synaptic plasticity in stress-responsive brain regions following chronic variable stress. Physiol Behav. 2011;104:242-7.

187. Naninck EF, Hoeijmakers L, Kakava-Georgiadou N, Meesters A, Lazic SE, Lucassen PJ, Korosi A: Chronic early life stress alters developmental and adult neurogenesis and impairs cognitive function in mice. Hippocampus 2014.

188. Peters M, Mizuno K, Ris L, Angelo M, Godaux E, Giese KP. Loss of Ca2+/ calmodulin kinase kinase beta affects the formation of some, but not all, types of hippocampus-dependent long-term memory. J Neurosci. 2003;23:9752-60.

189. Blaeser F, Sanders MJ, Truong N, Ko S, Wu LJ, Wozniak DF, et al. Long-term memory deficits in Pavlovian fear conditioning in Ca2+/calmodulin kinase kinase alpha-deficient mice. Mol Cell Biol. 2006;26:9105-15.

190. Lee DJ, Chen Y, Schlaug G. Corpus callosum: musician and gender effects. Neuroreport. 2003;14:205-9.

191. Hutchinson S, Lee LH, Gaab N, Schlaug G. Cerebellar volume of musicians. Cereb Cortex. 2003;13:943-9.

192. Nugent BM, Tobet SA, Lara HE, Lucion AB, Wilson ME, Recabarren SE, et al. Hormonal programming across the lifespan. Horm Metab Res. 2012;44:577-86.

193. Belleville S, Clément F, Mellah S, Gilbert B, Fontaine F, Gauthier S. Training-related brain plasticity in subjects at risk of developing Alzheimer's disease. Brain. 2011;134:1623-34.

194. Kirkness CJ, Burr RL, Mitchell PH, Newell DW. Is there a sex difference in the course following traumatic brain injury? Biol Res Nurs. 2004;5:299-310.

195. Tomassini V, Palace J. Multiple sclerosis lesions: insights from imaging techniques. Expert Rev Neurother. 2009;9:1341-59.

196. Voskuhl RR, Gold SM. Sex-related factors in multiple sclerosis susceptibility and progression. Nat Rev Neurol. 2012;8:255-63.

197. Dachtler J, Hardingham NR, Fox K. The role of nitric oxide synthase in cortical plasticity is sex specific. J Neurosci. 2012;32:14994-9.

198. Bazarian JJ, Blyth B, Mookerjee S, He H, McDermott MP. Sex differences in outcome after mild traumatic brain injury. J Neurotrauma. 2010;27:527-39. 
199. Stein DG. Progesterone exerts neuroprotective effects after brain injury. Brain Res Rev. 2008:57:386-97.

200. Tyagi E, Agrawal R, Ying Z, Gomez-Pinilla F. TBI and sex: crucial role of progesterone protecting the brain in an omega-3 deficient condition. Exp Neurol. 2014;253:41-51.

201. Sayeed I, Stein DG. Progesterone as a neuroprotective factor in traumatic and ischemic brain injury. Prog Brain Res. 2009;175:219-37.

202. Coronado VG, Xu L, Basavaraju SV, McGuire LC, Wald MM, Faul MD, et al. Surveillance for traumatic brain injury-related deaths - United States, 1997-2007. MMWR Surveill Summ. 2011;60:1-32.

203. Kraus JF, Peek-Asa C, McArthur D. The independent effect of gender on outcomes following traumatic brain injury: a preliminary investigation. Neurosurg Focus. 2000;8:e5.

204. Broshek DK, Kaushik T, Freeman JR, Erlanger D, Webbe F, Barth JT. Sex differences in outcome following sports-related concussion. J Neurosurg. 2005;102:856-63.

205. Covassin T, Schatz P, Swanik CB. Sex differences in neuropsychological function and post-concussion symptoms of concussed collegiate athletes. Neurosurgery. 2007:61:345-50. discussion 350-341.

206. Colvin AC, Mullen J, Lovell MR, West RV, Collins MW, Groh M. The role of concussion history and gender in recovery from soccer-related concussion. Am J Sports Med. 2009;37:1699-704

207. Wunderle T, Eriksson D, Schmidt KE. Multiplicative mechanism of lateral interactions revealed by controlling interhemispheric input. Cereb Cortex. 2013;23:900-12.

208. Wunderle K, Hoeger KM, Wasserman E, Bazarian JJ. Menstrual phase as predictor of outcome after mild traumatic brain injury in women. J Head Trauma Rehabil. 2014:29:E1-8.

209. Brooks BL, Khan S, Daya H, Mikrogianakis A, Barlow KM. Neurocognition in the emergency department after a mild traumatic brain injury in youth. J Neurotrauma. 2014;31:1744-9.

210. Fakhran S, Yaeger K, Collins M, Alhilali L. Sex differences in white matter abnormalities after mild traumatic brain injury: localization and correlation with outcome. Radiology. 2014;272:815-23.

211. Pantano P, Mainero C, Lenzi D, Caramia F, lannetti GD, Piattella MC, et al. A longitudinal fMRI study on motor activity in patients with multiple sclerosis Brain. 2005:128:2146-53.

212. Pantano P, lannetti GD, Caramia F, Mainero C, Di Legge S, Bozzao L, et al. Cortical motor reorganization after a single clinical attack of multiple sclerosis. Brain. 2002;125:1607-15

213. Liu C, Liu Y, Li W, Wang D, Jiang T, Zhang Y, et al. Increased regional homogeneity of blood oxygen level-dependent signals in occipital cortex of early blind individuals. Neuroreport. 2011;22:190-4.

214. Mori F, Rossi S, Piccinin S, Motta C, Mango D, Kusayanagi H, et al. Synaptic plasticity and PDGF signaling defects underlie clinical progression in multiple sclerosis. J Neurosci. 2013;33:19112-9.

215. Mori F, Kusayanagi H, Nicoletti CG, Weiss S, Marciani MG, Centonze D. Cortical plasticity predicts recovery from relapse in multiple sclerosis. Mult Scler. 2014; $20: 451-7$

216. Teuscher C, Noubade R, Spach K, McElvany B, Bunn JY, Fillmore PD, et al. Evidence that the $Y$ chromosome influences autoimmune disease in male and female mice. Proc Natl Acad Sci U S A. 2006;103:8024-9.

217. Lai MC, Lombardo MV, Auyeung B, Chakrabarti B, Baron-Cohen S. Sex/gender differences and autism: setting the scene for future research. J Am Acad Child Adolesc Psychiatry. 2015;54:11-24.

\section{Submit your next manuscript to BioMed Central and take full advantage of:}

- Convenient online submission

- Thorough peer review

- No space constraints or color figure charges

- Immediate publication on acceptance

- Inclusion in PubMed, CAS, Scopus and Google Scholar

- Research which is freely available for redistribution

Submit your manuscript at www.biomedcentral.com/submit 